Article

\title{
Dermal Delivery of Selected Polyphenols from Silybum marianum. Theoretical and Experimental Study
}

\author{
Pavel Kosina $1,+\left(\mathbb{D}\right.$, Markéta Paloncýová $2,3,+\mathbb{C}$, Alena Rajnochová Svobodová ${ }^{1}$, \\ Bohumil Zálešák ${ }^{4}$, David Biedermann ${ }^{5}$, , Jitka Ulrichová ${ }^{1}$ and Jitka Vostálová ${ }^{1, *(1)}$ \\ 1 Department of Medical Chemistry and Biochemistry, Faculty of Medicine and Dentistry, Palacký University, \\ Hněvotínská 3, 77515 Olomouc, Czech Republic; pavel.kosina@upol.cz (P.K.); \\ alena.rajnochova@upol.cz (A.R.S.); jitka.ulrichova@upol.cz (J.U.) \\ 2 Regional Centre of Advanced Technologies and Materials, Department of Physical Chemistry, Faculty of \\ Science, Palacký University, tř. 17 listopadu 12, 77146 Olomouc, Czech Republic; \\ marketa.paloncyova@upol.cz \\ 3 KTH Royal Institute of Technology, School of Engineering Sciences in Chemistry, Biotechnology and Health, \\ Department of Theoretical Chemistry \& Biology, S-106 91 Stockholm, Sweden \\ 4 Department of Plastic and Aesthetic Surgery, University Hospital Olomouc, I. P. Pavlova 6, 77900 Olomouc, \\ Czech Republic; bohumil.zalesak@fnol.cz \\ 5 Institute of Microbiology, Laboratory of Biotransformation, Academy of Sciences of the Czech Republic, \\ Vídeňská 1083, 14220 Prague, Czech Republic; biedermann@biomed.cas.cz \\ * Correspondence: jitka.vostalova@upol.cz; Tel.: +420-585-632-316 \\ + The contribution as the first author was equal.
}

Received: 6 December 2018; Accepted: 21 December 2018; Published: 24 December 2018

check for updates

\begin{abstract}
Silymarin is a well-known standardized extract from the seeds of milk thistle (Silybum marianum L., Asteraceae) with a pleiotropic effect on human health, including skin anticancer potential. Detailed characterization of flavonolignans properties affecting interactions with human skin was of interest. The partition coefficients $\log P_{o w}$ of main constitutive flavonolignans, taxifolin and their respective dehydro derivatives were determined by a High Performance Liquid Chromatography (HPLC) method and by mathematical (in silico) approaches in $n$-octanol/water and model lipid membranes. These parameters were compared with human skin intake ex vivo. The experimental $\log P_{\text {ow }}$ values for individual diastereomers were estimated for the first time. The replacement of $n$-octanol with model lipid membranes in the theoretical lipophilicity estimation improved the prediction strength. During transdermal transport, all the studied compounds permeated the human skin ex vivo; none of them reached the acceptor liquid. Both experimental/theoretical tools allowed the studied polyphenols to be divided into two groups: low (taxifolin, silychristin, silydianin) vs. high (silybin, dehydrosilybin, isosilybin) lipophilicity and skin intake. In silico predictions can be usefully applied for estimating general lipophilicity trends, such as skin penetration or accumulation predictions. However, the theoretical models cannot yet provide the dermal delivery differences of compounds with very similar physico-chemical properties; e.g., between diastereomers.
\end{abstract}

Keywords: Silybum marianum; flavonolignans; flavonoids; experimental and computational hydrophobicity; theoretical lipid membrane models; skin intake

\section{Introduction}

The primary function of the skin is to form a barrier between the body and the environment that is essential for maintaining body homeostasis. The epidermal barrier prevents excessive trans-epidermal 
loss of water, electrolytes or heat, but also serves as a barrier to the entry of harmful environmental toxic substances and infectious microorganisms or protects the body against damage caused by physical stimuli such as heat or radiation. The outermost layer of the skin, the stratum corneum, although very thin provides the main barrier to the transport of most topically applied compounds. The stratum corneum is formed from denucleated, keratin-filed, non-living cells called corneocytes that are anchored in a lipid matrix (major components include ceramides, fatty acids, and cholesterol). With its specific composition and morphology, the stratum corneum forms a unique biomembrane that is about a thousand times less permeable to water and compounds than other membranes in the body [1,2]. The cutaneous delivery of substances represents an attractive option for the treatment or prevention of various dermatological conditions with minimal side-effects and avoids metabolic biotransformation that may occur in the liver. However, the effective barrier function of the skin limits the use of many compounds as transdermal agents [2]. Therefore, a promising candidate for dermatological application has to cross the stratum corneum barrier and reach viable cells in the deeper layers of the epidermis and dermis.

Silymarin (SM) is a multicomponent extract from the seeds of the milk thistle (Silybum marianum L., Asteraceae). S. marianum is one of the oldest known herbal plants, and has been widely used in traditional European medicine for over two thousand years, especially for treating liver disorders. The main polyphenolic component of SM is the flavonolignan silybin (SB) [3]. Other components in considerable amounts include isosilybin (ISB), silychristin (SC), silydianin (SD) and their flavonoid precursor taxifolin (TA). Dehydrosilybin (DSB) is also present in small amounts [4]. The studied compounds' structures, including available diastereomers, are presented in Figure 1.

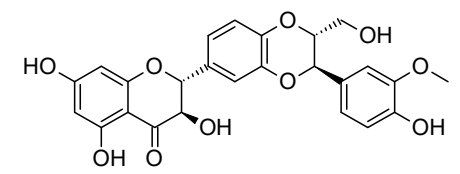

Silybin A (SB A)<smiles>COc1cc(C2Oc3ccc([C@@H]4Oc5cc(O)cc(O)c5C(=O)C4O)cc3OC2CO)ccc1O</smiles>

Isosilybin A (ISB A)

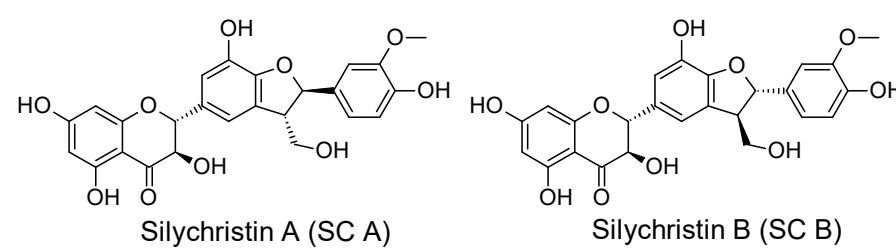

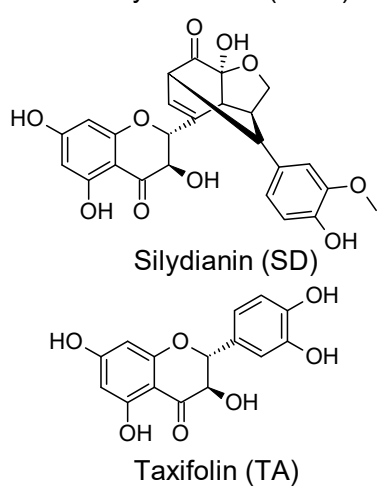<smiles>COc1cc([C@H]2Oc3cc([C@H]4Oc5cc(O)cc(O)c5C(=O)[C@H]4O)ccc3OC2CO)ccc1O</smiles>

Silybin B (SB B)<smiles></smiles>
Isosilybin B (ISB B)

Silychristin B (SC B)

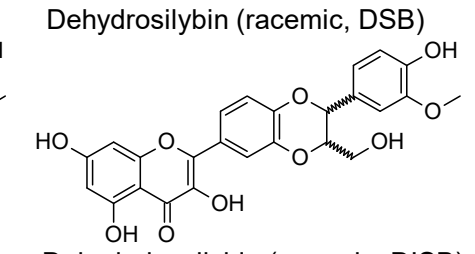

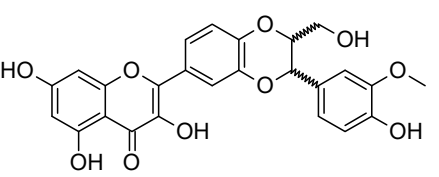

Dehydrosilybin (racemic, DSB)<smiles></smiles>

Dehydrosilychristin (racemic, DSC)

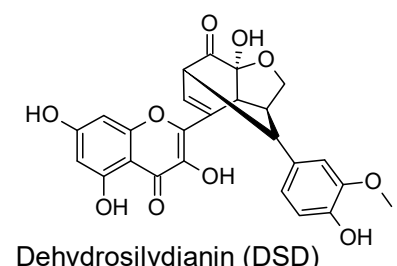<smiles>CC(=O)C(Oc1c(O)cc(O)cc1-c1ccc(O)c(O)c1)C(=O)O</smiles>

Figure 1. Structure of studied polyphenols. 
Besides the above-mentioned congeners of silybin, a lot of minor flavonolignans have been identified to date [5-7]. Multiple biological actions including antioxidant, anti-inflammatory, immunomodulatory or cytoprotective, make SM and SB attractive for dermatological applications. Therefore, the beneficial effects of SM and SB have been studied on skin carcinogenesis induced chemically [8] or by chronic exposure to UVB light [9], on skin disorders such as contact dermatitis [10], skin hyperpigmentation (melasma) [11], and wound healing [12]. Although many in vivo or clinical studies with SM/SB topical application were conducted, there is minimal information on the skin absorption and permeability (bioavailability) of SB and other SM components.

Efforts to characterize the interactions of compounds with biological membranes have led to an investigation of the hydrophobicity of the utilized molecules [13,14]. Apart from experimental methods, a significant amount of work has been done on in silico predictions in recent years. Hydrophobicity in terms of the widely used $n$-octanol/water partition coefficient $\log P_{\text {ow }}$ can be predicted by structure-based tools, such as the freely available AlogP [15], Molinspiration [16] etc. Most of these methods use topological descriptors, or the fragmentation of molecules to functional groups or atoms. From fitting a large number of available experimental data, the effects of the molecular fragments present in molecules on their $\log P_{o w}$ can be estimated. These methods are strictly focused on $\log P_{o w}$ and work well, especially among molecules similar to the training set. Quantum-calculation based methods or molecular dynamics simulations are another possibility for in silico predictions. These methods are more general and usually not focused on the prediction of a single property. Their performance in terms of $\log P_{o w}$ can be worse, but they are not limited to a single case or a certain molecular type. Currently available tools for $\log P_{\text {ow }}$ prediction have been summarized in a review by Tetko and Poda [17].

The aim of this study was (i) to determine the partition coefficients log $P_{o w}$ of selected polyphenols of SM (SB, ISB, SD, DSB, SC, TA) as well as dehydroderivatives dehydrosilychristin (DSC), dehydrosilydianin (DSD), dehydroisosilybin (DISB), and quercetin (QU) were included in the study (see Figure 1) by High Performance Liquid Chromatography (HPLC) and by mathematical (in silico) approaches in an n-octanol/water system and to compare the obtained values; (ii) to calculate the permeability coefficients of selected SM components for model membranes (bilayer of dioleoylphosphatidylcholine, ceramide or mixture ceramide, cholesterol and lignoceric acid) and to compare them with experimental data obtained using human skin fixed in Franz diffusion cells.

\section{Results and Discussions}

\subsection{Experimental Partition Coefficients $\log P_{\text {ow,exp }}$}

The partition coefficients $\left(\log P_{o w, \text { exp }}\right)$ of studied polyphenols including available diastereomers were obtained using reverse phase HPLC in the $\mathrm{pH}$ range of 4.5-8.5. For evaluating the studied compounds' hydrophobicity, $\log P_{o w, \exp }$ of all reference substances were used except for aniline, whose $\log P_{\text {ow,exp }}$ value (0.9) was conspicuously lower than that of the other reference substances (their individual $\log P_{o w}$ and applied amounts are presented in Appendix Table A1). Aniline was only used to evaluate the $\log P_{\text {ow,exp }}$ of TA at $\mathrm{pH} 8.5$ due to a big negative shift in the TA $\log P_{\text {ow,exp }}$ value.

The relation between the capacity factor $k$ and $\log P_{o w}$ of reference compounds at various $\mathrm{pH}$ of mobile phase, employing quadratic equations, was evaluated. The recommended application of the linear equation [14] based on reference compound capacity factors (retention times) and $\log P_{\text {ow }}$ values for evaluating the test compounds' $\log P_{o w}$ gave only an $r^{2}$ value of 0.89 , see Table A2. The application of the quadratic equation resulted in obtaining more valuable data for the studied compounds' log $P_{\text {ow,exp }}$ evaluation $\left(\mathrm{r}^{2} \sim 0.99\right)$, see Table A2. Therefore, the quadratic equations were employed to estimate the $\log P_{o w, \exp }$ values of the studied compounds.

A minimal influence of temperature $\left(25^{\circ} \mathrm{C} \sim\right.$ recommended by OECD107 [13] $)$ vs. $32{ }^{\circ} \mathrm{C} \sim$ corresponding to the skin surface temperature) on $\log P_{o w, \exp }$ values was found (data not shown). Similarly, a minor effect of temperature was found for theoretical (calculation) models (data not shown). 
The $\log P_{\text {ow,exp }}$ values of the studied polyphenols, including data for diastereomers, were evaluated in $5 \mathrm{mM}$ phosphate (Table 1), additionally in $5 \mathrm{mM}$ formate and $5 \mathrm{mM}$ acetate buffer as well, in a gradient with methanol at $25^{\circ} \mathrm{C}$ with the $\mathrm{pH}$ range of 4.5-8.5. A minimal effect of mobile phase composition (phosphate vs. formate vs. acetate) was found (Tables 1, A3 and A4). Application of acetate or formate buffers instead of phosphate allows mass spectrometry identification of studied compounds.

Table 1. Hydrophobicity (log $\left.P_{\text {ow,exp }}\right)$ of studied compounds in phosphate buffers.

\begin{tabular}{|c|c|c|c|c|c|}
\hline \multirow{2}{*}{ Compound } & \multicolumn{5}{|c|}{$\log P_{o w, \exp }$} \\
\hline & 4.5 & 5.5 & 6.5 & 7.5 & 8.5 \\
\hline Taxifolin & $1.761 \pm 0.017$ & $1.763 \pm 0.002$ & $1.674 \pm 0.017$ & $1.486 \pm 0.026$ & $0.802 \pm 0.046$ \\
\hline Silychristin A & $2.045 \pm 0.010$ & $2.042 \pm 0.003$ & $1.952 \pm 0.017$ & $1.786 \pm 0.021$ & $1.705 \pm 0.003$ \\
\hline Silydianin & $2.076 \pm 0.011$ & $2.077 \pm 0.010$ & $1.964 \pm 0.019$ & $1.805 \pm 0.017$ & $1.742 \pm 0.004$ \\
\hline Dehydrosilydianin & $2.178 \pm 0.009$ & $2.181 \pm 0.008$ & $2.108 \pm 0.014$ & $1.948 \pm 0.024$ & $1.843 \pm 0.004$ \\
\hline Quercetin & $2.269 \pm 0.010$ & $2.266 \pm 0.006$ & $2.197 \pm 0.015$ & $1.979 \pm 0.030$ & $1.778 \pm 0.005$ \\
\hline Silybin A & $2.314 \pm 0.008$ & $2.310 \pm 0.010$ & $2.180 \pm 0.024$ & $1.972 \pm 0.025$ & $1.872 \pm 0.002$ \\
\hline Silybin B & $2.346 \pm 0.006$ & $2.336 \pm 0.009$ & $2.203 \pm 0.019$ & $1.999 \pm 0.023$ & $1.904 \pm 0.002$ \\
\hline Dehydrosilychristin & $2.425 \pm 0.003$ & $2.420 \pm 0.007$ & $2.352 \pm 0.016$ & $2.162 \pm 0.029$ & $2.025 \pm 0.010$ \\
\hline
\end{tabular}

The letters A or B in the name of compounds mean that diastereomers of the compound exist and they were separated by a chromatographic system under the applied experimental conditions. Data are presented as mean \pm S.D., $n=4$.

Of all the studied compounds, the lowest $\log P_{\text {ow,exp }}$ values were found for TA and the highest ones for DISB at all $\mathrm{pH}$ values. Among flavonolignans and their dehydro derivatives, SC A exhibited the lowest $\log P_{o w, e x p}$ value. The hydrophobicity of flavonolignans in increasing order was as follows: SC A $<$ SD < SC B < DSD < SB A < SB B < DSC < ISB A < ISB B < DSB < DISB. Flavonolignan dehydro derivatives were more hydrophobic than the corresponding parent substances. The same effect was observed with the pair of flavonoids TA and QU. The increasing $\mathrm{pH}$ value of the mobile phase decreased the $\log P_{\text {ow, exp }}$ value for all polyphenols (Table 1).

\subsection{Calculated Partition Coefficients $\log P_{\text {ow, calc }}$}

The computational tools for lipophilicity evaluation $\left(\log P_{o w, c a l c}\right), A \log P$ [15], Molinspiration [16] and COSMOtherm 15 [18] showed a slightly different order of the molecular hydrophobicity of the studied compounds compared to the experimental evaluation, but the general trends remained the same (Table 2).

TA was the least lipophilic molecule and DISB was the most hydrophobic. Also, the dehydro derivatives (DISB, DSB, DSC and QU) were more lipophilic than their respective parent substances, which agrees with experimental data. The AlogP tool predicted $\log P_{o w, c a l c}$ values for the studied compounds within the range of 1.1-2.8 and the Molinspiration tool computed $\log P_{\text {ow, calc }}$ values within the range of 0.7-2.4. Using COSMOtherm 15, a wider range of $\log P_{\text {ow,calc }}$ values were obtained (1.0-4.2) than with the above-mentioned tools (Table 2$)$. The correlation of the experimental $\left(\log P_{\text {ow,exp }}\right)$ and calculated $\left(\log P_{o w, c a l c}\right)$ data in terms of linear fit, correlation coefficient $\left(\mathrm{r}^{2}\right)$ and mean differences (MD) was evaluated (for data see Appendix Figure A1 and Table A5). 
Table 2. Hydrophobicity of studied compounds predicted by computational tools as octanol/water partition coefficient $\left(\log P_{\text {ow, calc }}\right)$ and lipid/water partition coefficient $\left(\log P_{l w, c a l c}\right)$ in membrane models.

\begin{tabular}{|c|c|c|c|c|c|c|}
\hline \multirow{2}{*}{ Compound } & \multicolumn{3}{|c|}{$\log P_{o w, c a l c}$} & \multicolumn{3}{|c|}{$\log P_{l w, \text { calc }}$} \\
\hline & COSMOtherm & Molinspiration & $A \log P$ & CER & DOPC & CLC \\
\hline Taxifolin & 1.01 & 0.71 & 1.07 & 1.14 & 1.49 & 0.22 \\
\hline Silychristin A & 2.55 & 1.26 & 2.13 & 1.64 & 2.35 & 1.10 \\
\hline Silydianin & 1.29 & 1.21 & 1.84 & 2.28 & 2.25 & 1.51 \\
\hline Silychristin B & 2.51 & 1.26 & 2.13 & 1.76 & 2.35 & 1.06 \\
\hline Dehydrosilydianin & 1.07 & 1.21 & 1.84 & 2.13 & 2.08 & 1.34 \\
\hline Quercetin & 2.17 & 1.68 & 1.81 & 1.80 & 2.17 & 0.79 \\
\hline Silybin A & 3.30 & 1.47 & 2.35 & 2.21 & 3.06 & 1.93 \\
\hline Silybin B & 3.20 & 1.47 & 2.35 & 2.19 & 2.90 & 1.83 \\
\hline Dehydrosilychristin & 3.61 & 2.24 & 2.57 & 2.26 & 3.09 & 1.50 \\
\hline Isosilybin A & 3.56 & 1.47 & 2.35 & 2.82 & 3.44 & 2.47 \\
\hline Isosilybin B & 3.25 & 1.47 & 2.35 & 2.46 & 3.17 & 2.16 \\
\hline Dehydrosilybin & 4.17 & 2.44 & 2.80 & 2.78 & 3.68 & 2.57 \\
\hline Dehydroisosilybin & 4.18 & 2.44 & 2.81 & 3.42 & 3.97 & 3.09 \\
\hline
\end{tabular}

The lowest $\mathrm{r}^{2}$ values were found with COSMOtherm 15 and the highest with Molinspiration ( $\mathrm{pH}$ 4.5-7.5) and $\mathrm{A} \log \mathrm{P}(\mathrm{pH}$ 8.5). The lowest $\mathrm{MD}$ were obtained with AlogP over the whole $\mathrm{pH}$ range (Table A5).

\subsection{Lipid/Water Partition Coefficients $\log P_{l w, \text { calc }}$}

Apart from n-octanol/water partition $\left(\log P_{o w, c a l c}\right)$, lipid/water partition coefficients $(\log$ $\left.P_{l w, c a l c}\right)$ in membrane models (dioleoylphosphatidylcholine (DOPC), ceramide (CER) and ceramide, lignoceric acid and cholesterol mixture (CLC)) were calculated using COSMOmic (Table 2). The best correlation between $\log P_{l w, \text { calc }}$ and $\log P_{o w, e x p}$ was obtained using the DOPC membrane model, where $\mathrm{r}^{2}$ reached up to 0.84 with respect to the data at $\mathrm{pH} 4.5$ and 5.5. The correlation of $\log P_{l w, \text { calc }}$ values for CER and CLC membrane models with experimental data was lower than for the DOPC membrane model, as the $\mathrm{r}^{2}$ values varied from 0.75 to 0.82 . In terms of MD, the CER membrane model performed best (MD in the range of 0.24 to 0.37 over the whole $\mathrm{pH}$ range). In the DOPC membrane model, the MD increased with $\mathrm{pH}$, while in the CLC membrane model the MD decreased with $\mathrm{pH}$. Although working on a very different principle, the CER membrane model appeared to work with a similar level of accuracy to AlogP in terms of MD and together with the DOPC membrane model scored very well in terms of $r^{2}$ (for data see Appendix Figure A1 and Table A5).

\subsection{Skin Permeability of Polyphenols}

The skin permeability of polyphenols was studied using Franz diffusion cells with human skin. None of the studied compounds were found in the acceptor liquid, however all were found in the tissue. The skin intake of the studied compounds during transdermal transport was influenced by the ethanol content and $\mathrm{pH}$ of the donor liquid. The results are presented in Table 3 and expressed as the amount of individual polyphenols in pmol per $\mathrm{g}$ of skin tissue per $24 \mathrm{~h}$. 
Table 3. Skin intake of studied compounds evaluated by transdermal transport.

\begin{tabular}{|c|c|c|c|c|c|c|c|c|}
\hline \multirow{4}{*}{ Compound } & \multicolumn{8}{|c|}{ Concentration (pmol $\mathrm{g}^{-1}$ of Skin) } \\
\hline & \multicolumn{4}{|c|}{ pH 6.5} & \multicolumn{4}{|c|}{ pH 8.5} \\
\hline & \multicolumn{4}{|c|}{ EtOH $(\%, v / v)$} & \multicolumn{4}{|c|}{ EtOH $(\%, v / v)$} \\
\hline & 0 & 5 & 10 & 15 & 0 & 5 & 10 & 15 \\
\hline Taxifolin & 3101 & 4237 & 2068 & 2228 & 2099 & 1518 & 1202 & 2022 \\
\hline Silychristin & 16717 & 8655 & 5431 & 5690 & 5358 & 5166 & 2912 & 3275 \\
\hline Silydianin & 6997 & 6606 & 7809 & 3457 & 4966 & 2204 & 6257 & 6129 \\
\hline Silybin & 53093 & 39744 & 15984 & 31531 & 17676 & 26824 & 13258 & 7311 \\
\hline Quercetin & 56230 & 78622 & 28628 & 49162 & 6586 & 6185 & 10935 & 2699 \\
\hline Isosilybin & 77643 & 71638 & 47375 & 29113 & 31985 & 20131 & 8591 & 7969 \\
\hline Dehydrosilybin & 45105 & 45145 & 22399 & 35810 & 50248 & 30352 & 28477 & 26721 \\
\hline
\end{tabular}

The studied compounds were applied to the skin membrane at a concentration of $50 \mu \mathrm{M}$ in the donor liquid and incubated at $32{ }^{\circ} \mathrm{C}$. After $24 \mathrm{~h}$, the skin was collected for evaluating the content of the studied compounds.

Apart from DSB, the skin content of all polyphenols was lower when applied in donor liquid with $\mathrm{pH} 8.5$ than $\mathrm{pH}$ 6.5. When donor liquid with $\mathrm{pH} 6.5$ was used, the skin intake of polyphenols was in the order: $\mathrm{TA}<\mathrm{SD}<\mathrm{SC}<\mathrm{DSB}<\mathrm{SB}<\mathrm{QU}<\mathrm{ISB}$ and at $\mathrm{pH} 8.5$ it was $\mathrm{TA}<\mathrm{SD}<\mathrm{SC}<\mathrm{QU}$ $<\mathrm{SB}<\mathrm{ISB}<\mathrm{DSB}$. For the main silymarin constituent (SB), both diastereomers SB A and SB B were determined. The amount of SB B in skin was found to be slightly higher than that of SB A (data not shown). The skin content of QU dramatically decreased ( 8.5 times), when QU was applied in donor liquid with $\mathrm{pH} 8.5$.

Increasing ethanol content had a mostly negative effect on the polyphenol penetration into the skin (Table 3). The skin bioavailability of a substance is usually predicted by its $\log P_{\text {ow }}$ value [2]. Therefore the $\log P_{\text {ow,exp }}$ values were compared with the skin intake of polyphenols. At $\mathrm{pH} 6.5$, the correlation coefficient $\mathrm{r}^{2}$ of $\log P_{\text {ow, exp }}$ and logarithm of skin intake varied between 0.54 to 0.60 (see Appendix B-Table A6). However, inspecting the data (Figure 2), DSB was identified as an outlier; after its exclusion the $\mathrm{r}^{2}$ between $\log P_{\text {owwexp, }}$ at $\mathrm{pH} 6.5$ and the logarithm of the measured skin intake reached 0.94 (Table A6). The $\log P_{\text {ow,exp }}$ values at $\mathrm{pH} 8.5$ were not as suitable for estimating the skin intake as the data obtained at pH 6.5. Generally, the highest correlation was observed for ethanol-free systems.
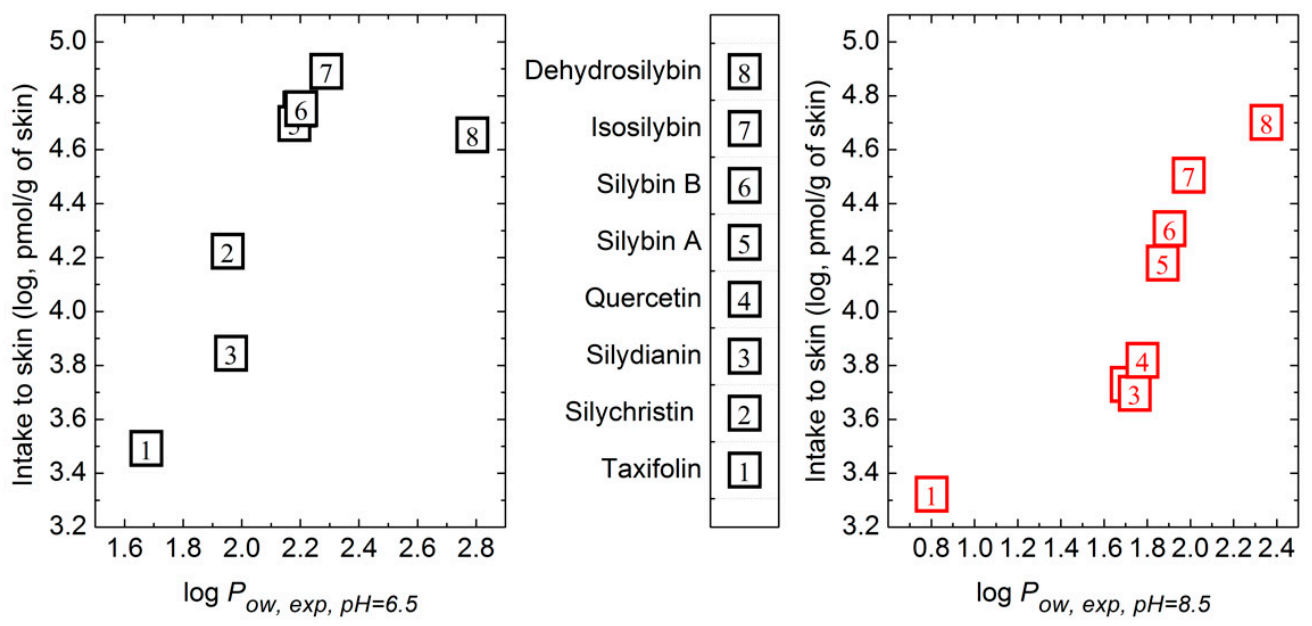

Figure 2. Relation of compounds' skin intake to their lipophilicity. The relation of skin intake to experimental $n$-octanol/water partition coefficient $\left(\log P_{\text {ow,exp }}\right)$ at $\mathrm{pH} 6.5$ is presented on the left; the relation of skin intake to $\log P_{\text {ow,exp }}$ at $\mathrm{pH} 8.5$ is shown on the right. 


\subsection{Calculated Permeability of Polyphenols log Perm}

From the free energy profiles on all membrane models (CER, CLC and DOPC, see Figure 3) obtained by COSMOmic, the permeability (log Perm) of polyphenols were calculated (Table 4). The order of free energy profiles of studied polyphenols (Figure 3) as well as a penetration barrier $\left(\Delta G^{\text {pen }}\right)$ and Perm (Table 4$)$ corresponds to lipophilicity $\left(\log P_{l w, c a l c}\right)$, calculated by theoretical tool (COSMOmic), see Table 2. The lowest free energy profiles were found for DISB and DSB; and the highest one for TA.

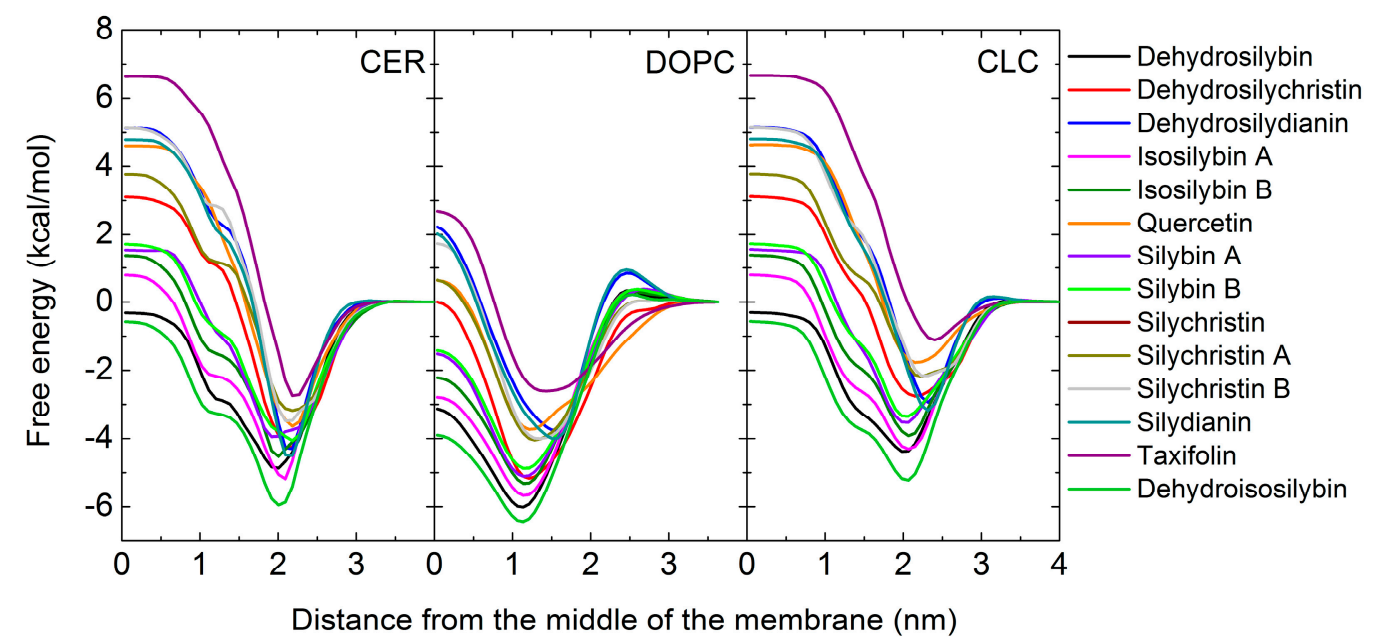

Figure 3. Free energy profiles of studied compound in ceramide (CER), dioleoylphosphatidylcholine (DOPC) and ceramide, lignoceric acid and cholesterol mixture (CLC) membrane models.

Table 4. Permeability $(\log$ Perm $)$ and penetration barrier $\left(\Delta G^{p e n}\right)$ calculated from COSMOmic free energy profiles in membrane models.

\begin{tabular}{lccccccc}
\hline \multirow{2}{*}{ Compound } & \multicolumn{3}{c}{$\log$ Perm } & & \multicolumn{3}{c}{$\Delta G^{\text {pen }}$ (kcal/mol) } \\
\cline { 2 - 3 } \cline { 6 - 8 } & CER & DOPC & CLC & & CER & DOPC & CLC \\
\hline Taxifolin & -4.56 & -1.44 & -4.67 & & 9.39 & 5.30 & 7.78 \\
Silychristin & -2.41 & -0.35 & -2.53 & & 6.96 & 4.69 & 5.96 \\
Silydianin & -3.40 & -0.95 & -3.31 & & 9.29 & 6.02 & 7.98 \\
Silybin A & -1.01 & -0.28 & -1.07 & & 5.49 & 3.59 & 5.08 \\
Silybin B & -1.05 & -0.30 & -1.13 & & 5.77 & 3.45 & 5.07 \\
Quercetin & -3.11 & -0.25 & -3.23 & & 8.24 & 4.37 & 6.41 \\
Isosilybin A & -0.51 & -0.29 & -0.56 & & 5.97 & 2.88 & 5.10 \\
Dehydrosilybin & -0.28 & -0.26 & -0.24 & & 4.55 & 2.88 & 4.07 \\
\hline
\end{tabular}

CER-ceramide, DOPC—dioleoylphosphatidylcholine, CLC—ceramide, lignoceric acid and cholesterol mixture. The letters A or B for silybin mean that calculations were done for its respective diastereomers.

\subsection{Calculated Partition Coefficient $\log P_{l w, c a l c}$ and Permeability $\log$ Perm Correlation with Polyphenols' Skin Intake}

The experimental skin intake was compared to $\log P_{l w, c a l c}$ and $\log$ Perm (for data see Appendix B-Table A7). For the skin intake at pH 6.5 (no ethanol) after excluding QU, a better correlation was found with $\log$ Perm in CER and CLC membrane models $\left(\mathrm{r}^{2}=0.95\right.$ and 0.94). The DOPC membrane model did not distinguish well between more hydrophobic compounds, the correlation was lower. For the skin intake at $\mathrm{pH} 8.5$, a correlation was found with $\log P_{l w, c a l c}$ for all the membrane models used (Figure 4).

Of the computative $\log P_{o w}$ tools used, the best prediction of $\log P_{l w, c a l c,}$ was obtained with the DOPC membrane model $\left(\mathrm{r}^{2}=0.97\right)$. The ethanol content and/or $\mathrm{pH}$ increase in the donor liquid influenced the correlation between the skin intake (experimental data) and $\log$ Perm or $\log P_{l w, c a l c}$. 
For both $\mathrm{pH}$ values and ethanol content $(5$ and $10 \%(v / v))$ a decrease in $\mathrm{r}^{2}$ was observed. At $\mathrm{pH}$ 6.5 and an ethanol concentration of $15 \%(v / v)$ an increase in $\mathrm{r}^{2}$ was found for all membrane models (for data see Appendix B Table A7). A clear linear dependence was found between log Perm and the skin intake for the less hydrophobic compounds (TA, SD, SC). The calculation was unable to clearly distinguish between the highly hydrophobic compounds, as Perm depended exponentially on the highest free energy. The hydrophobic compounds with high $\log P_{l w, c a l c}$ (affected primarily by the lowest free energy well—see Material and Methods section: Design of computational of hydrophobicity of polyphenols) - did not show any significant dependence of the skin intake on log Perm at the DOPC membrane. For other membrane models, where the penetration free energy barrier is higher than with DOPC (Figure 3, Table 4), a dependence of skin intake on log Perm over the whole range was found, however with two outliers, DSB and QU.
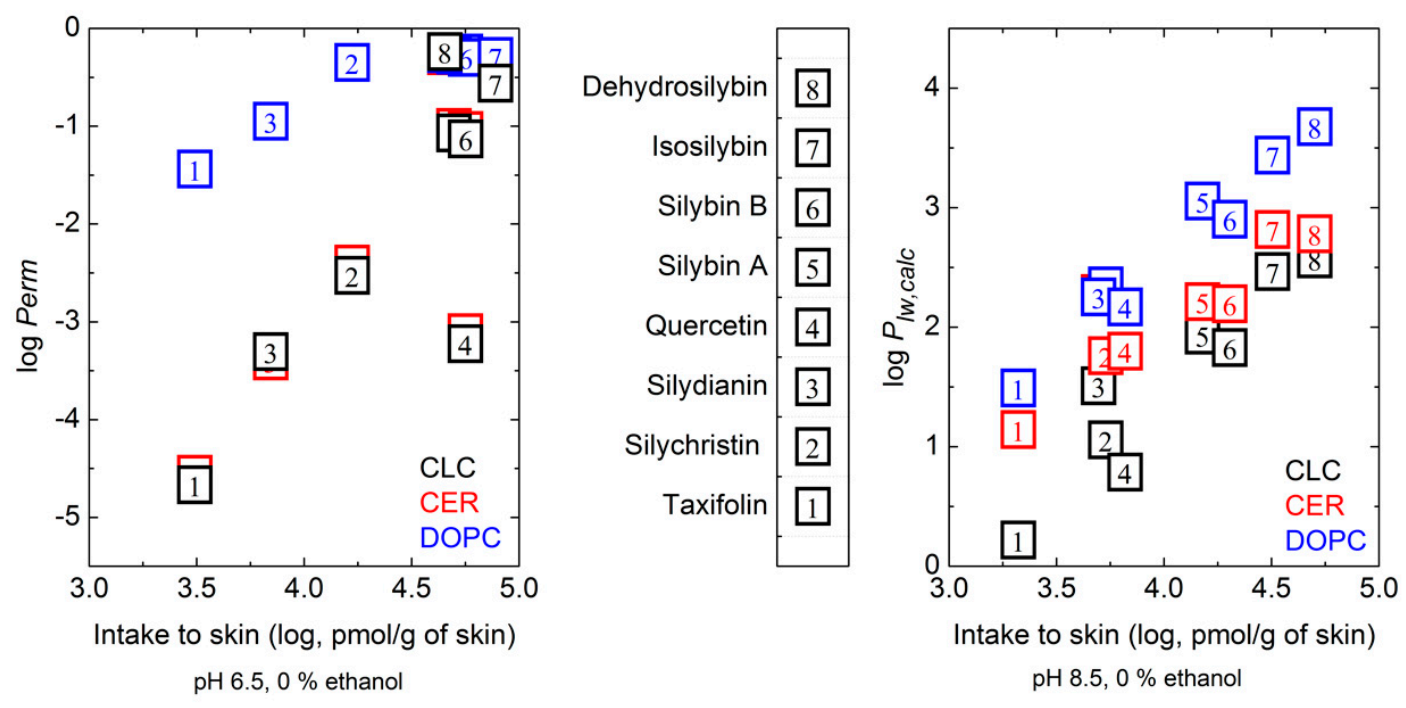

Figure 4. Relation between compounds' skin intake and calculated permeability or partition coefficients in lipid membrane models. The relation between the logarithms of the compounds' skin intake at pH 6.5 and calculated permeability (log Perm) in lipid membrane models is presented on the left; the logarithms of the compounds' skin intake at $\mathrm{pH} 8.5$ and calculated lipid membrane models partition coefficients $\left(\log P_{l w, \text { calc }}\right)$ is shown on the right. CER-ceramide, DOPC-dioleoylphosphatidylcholine, CLC-ceramide, lignoceric acid and cholesterol mixture.

\subsection{Discussions}

Despite the use of silymarin in dermatological preparations, a limited amount of information about the hydrophobicity of silymarin's polyphenols is available. Our study focused on characterizing the hydrophobicity of selected flavonolignans (including diastereomers and dehydro derivatives) and the flavonoids taxifolin and quercetin and their interaction with model membranes and human skin using theoretical and experimental tools.

For compounds with a possible dermal application, it is essential to be able to cross the lipids layer barrier of the stratum corneum and be soluble in both hydrophobic and hydrophilic environments. These ambivalent properties can be evaluated by the $n$-octanol/water partition coefficient [2]. The official OECD method, based on the partition of a studied compound between the water and $n$-octanol phases ( $n$-octanol/water partition coefficient; $\log P_{o w}$ ) measured by the shake flask method, imitates the compound's interaction with the biomembrane very well [13]. In this way the $\log P_{\text {ow }}$ also characterizes the partitioning of a compound between the lipophilic stratum corneum and the underlying hydrophilic living cells of the epidermis [2]. Today, instead of the shake flask method, another OECD Guideline, Test No. 117 using isocratic HPLC elution was applied [14], but in gradient elution mode [19]. The methods for $\log P_{o w}$ evaluation are based on a comparison of the $\log P_{o w}$ values of a set of reference compounds and their retention times (capacity factors) in a $\mathrm{C}_{18}$ chromatographic 
column with retention times and capacity factors of studied compounds [14]. The application of the HPLC method for estimating the $\log P_{o w}$ values of polyphenols has several advantages: a stable temperature during analysis, the application of small amounts of pure studied compounds as well as their mixtures with similar structure and/or similar physico-chemical properties. By the HPLC gradient elution method, the mixture of main constitutive $S$. marianum flavonolignans (SB, SC, SD, ISB), including diastereomers for SB, SC and ISB, and their respective dehydro derivatives (eleven individual compounds) as well as TA and its dehydro derivative QU could be separated in one run and the obtained data were suitable for the evaluation of $\log P_{\text {ow, exp }}$ values (Table 1).

Data for individual diastereomers of SB, SC and ISB as well as for DISB are published here for the first time. The $\log P_{o w, c a l c}$ values that we found for QU and TA (Table 2) are in agreement with reports by Maroziene et al. [20]. The $\log P_{\text {ow,exp }}$ value of QU corresponds to the data by Rothwell et al. [21]. Similarly, the $\log P_{\text {ow,exp }}$ values for the pair of flavonolignans DSB and SB obtained by the shake flask method published by Gažák et al. [22] agree with our data obtained by the HPLC method. Here we further found that the hydrophobicity of SM's compounds decreased with increasing $\mathrm{pH}$ in all applied solutions (mobile phases), which corresponds to the results for TA, SB, ISB, SC, SD obtained by the shake flask method [23]. A small effect of $\mathrm{pH}$ on $\log P_{\text {owwexp }}$ was observed at $\mathrm{pH}$ from 4.5 to 6.5. An obvious decrease in hydrophobicity $\left(\log P_{\text {ow, exp }}\right)$ was found from pH 6.5 to 8.5 (Table 1$)$. This phenomenon is connected with the ionization of ionizable groups in the studied compounds. The $\mathrm{pK}_{\mathrm{a} 1}$ value of SB, SC, SD [24], TA [25] and QU [26] is close to neutral $\mathrm{pH}(\sim 7.0)$ and $\mathrm{pK}_{\mathrm{a} 2}$ is $\sim 8.5$. The strongest decrease in $\log P_{\mathrm{ow}}$ in the case of TA at $\mathrm{pH} 8.5$ relates to its $\mathrm{pK}_{\mathrm{a}}$ values $\left(\mathrm{pK}_{\mathrm{a} 1} 7.1 ; \mathrm{pK}_{\mathrm{a} 2} 8.6\right.$; $\mathrm{pK}_{\mathrm{a} 3}$ 8.59; $\mathrm{pK}_{\mathrm{a} 4}$ 11.82) [25] as well. Generally, the neutral form of the molecule is more lipophilic than the deprotonated one. The order of the $\log P_{\text {owvexp }}$ of the studied polyphenols (TA, SB, SC, SD and ISB) was not the same as that found by Zeng et al. [23]. It could be caused by the experimental limitations of the shake flask method. Studied compounds can occur in both phases and also in an interphase; this phenomenon is eliminated in the reverse phase chromatography method used in our study.

The experimental evaluation of compound hydrophobicity is time-consuming, experimentally (the shake flask method) and financially (reverse phase HPLC based approaches) demanding and also unfavorable to the environment (does not follow green chemistry approaches) [19]. Currently a large number of sophisticated computational tools, based on various parameters, are available $[17,27,28]$. These in silico methods are helpful for screening a large set of compounds and for basic behavior classification in terms of compound hydrophobicity and bioavailability, reducing the amount of in vivo experiments or clinical trials [29]. On the other hand, the theoretical methods have some limitations, including the inability to properly simulate all situations in a real biological system (i.e., skin). In our study the tools COSMOtherm 15, AlogP and Molinspiration were used. COSMOtherm 15 is generally focused on the partitioning between fluid phases and not directly on $\log P_{o w}$, and does not consider the $\mathrm{pH}$ effect; therefore, it scored worst of the calculation methods used. At $\mathrm{pH} 4.5-7.5$, the highest correlation was obtained with Molinspiration and at $\mathrm{pH} 8.5$ with AlogP. This may be caused by AlogP's use of electrotopological state descriptors [30]. This is an atomic approach that also considers the valence state of the atoms, which may better reflect the experimental molecule ionization at $\mathrm{pH} 8.5$ (corresponding to the $\mathrm{pK}_{\mathrm{a}}$ of studied polyphenols). AlogP and Molinspiration tools are based on a large set of experimental $\log P_{o w}$ values and both are applicable around neutral $\mathrm{pH}$. None of the theoretical tools used were able to reflect the behavior of the set of polyphenols over the whole $\mathrm{pH}$ range (4.5-8.5). According to the correlations obtained, the choice of optimal $\log P_{\text {ow }}$ calculation tool should consider the desired real experimental conditions $\sim$ the real applicative conditions of the compound. When the studied polyphenols are in ionized form $\left(\mathrm{pH}\right.$ over $\mathrm{pK}_{\mathrm{a}}$ ) only the AlogP tool is able to estimate $\log P_{o w}$, calc values. At $\mathrm{pH}$ below $\mathrm{pK}_{\mathrm{a}}$, Molinspiration described the system best. The replacement of $n$-octanol with lipid membrane models (DOPC, CER or CLC) in COSMOmic improved the prediction strength. COSMOtherm and COSMOmic inputs are a 3D structure of the compound (conformational variability is considered) [18] and thus differentiation between diastereomers A and B is possible. The differences in the hydrophobicity of the diastereomers were too small to distinguish them, and this 
ability remains a benefit of experimental evaluation. ALogP and Molinspiration tools do not work with diastereomerism.

Although $n$-octanol/water partitioning $\log P_{\text {ow }}$ is taken as a gold standard for lipophilicity estimation [19], considering the lipophilicity directly in terms of the lipid/water partition coefficient log $P_{l w}$ predicts it better. However, using theoretical approaches to characterize the transdermal delivery in vivo is still complicated due to the complexity of the systems in terms of composition or the real interaction between human skin tissue and a topically applied compound. Therefore, both approaches were applied in our study. Many papers have demonstrated that increasing lipophilicity increases the skin permeation of compounds, and a $\log P_{o w}$ of 2-3 seems to be optimal. It is likely that these molecules with intermediate lipophilicity can permeate via both the lipid and polar microenvironments in the intercellular route [31]. Accordingly, most of the studied polyphenols are good candidates for dermal application, especially at acidic $\mathrm{pH}$ (4.5-6.5), see Table 1. Our transdermal transport data demonstrated that none of the studied compounds were able to penetrate through the skin, as none of them were detected in the acceptor liquid. However, all the polyphenols were found in the human skin (Table 3). In this way the human skin works as a trap and only the skin intake (accumulation) of polyphenols can be measured. QU skin intake should be taken with care, as the presented results on human skin were affected by QU instability in aqueous solutions that was previously reported [32]. Thus, with QU it is not possible to ensure a constant QU concentration in the donor liquid during experiments $(24 \mathrm{~h})$ as with the other studied polyphenols. Due to QU decomposition, the amount in the skin is most likely significantly reduced. A higher instability of QU occurs in alkaline $\mathrm{pH}$ [32], which corresponds with a lower amount of QU in the skin at the higher $\mathrm{pH}$ of $8.5 \mathrm{in}$ our experiments (Table 3). Therefore, correlations of the polyphenol skin intake with $\log$ Perm and $\log P_{l w, c a l c}$ were performed without QU.

Although the long-term practical use of silymarin, flavonolignan skin delivery is poorly documented. The previous work [33] that studied the in vitro delivery of SB, SD and SC using native, chemically, and physically modified mouse skin does not agree with our results (Table 3). In the mouse models, the flavonolignans were able to penetrate through the skin into the acceptor liquid $(\mathrm{SB}>\mathrm{SD}>\mathrm{SC}$ ). However, the human skin has a higher barrier function (more robust stratum corneum and thicker epidermis) than mouse skin and so mouse skin is not a fully accepted model to mimic the penetration of compounds through the human skin [34]. Nevertheless, SB deposition in mouse skin was notably higher than those of SC and SD [33], which corresponds to our data (Table 3). The order of polyphenol permeation through CER and CLC membrane models (Table 4) also partially agrees with the published data on mouse skin [33]. According to our data on the experimental skin uptake, the studied polyphenols can be divided into two groups: low intake (TA, SC, SD) and high intake (SB, DSB, ISB). This division also corresponded to their hydrophobicity based on theoretical data $\left(\log P_{o w, c a l c}, \log P_{l w, c a l c}\right)$ and experimental $\log P_{o w}$ values as well. Our results further showed a significant effect of $\mathrm{pH}$ on the skin intake of flavonolignans and flavonoids. All these properties may be important for designing dermal preparations containing these polyphenols.

\section{Materials and Methods}

\subsection{Studied Compounds}

Pure flavonolignans (SB, SC, SD and ISB) and their respective oxidized products (dehydrosilychristin (DSC), dehydrosilydianin (DSD), dehydroisosilybin (DISB) and dehydrosilybin (DSB)) were prepared at the Institute of Microbiology, Academy of Sciences of the Czech Republic, Prague, Czech Republic according to previously published studies. For SB and ISB, individual diastereomers were available [35]. SC (natural mixture of diastereomers) and SD were isolated from silymarin by Sephadex LH-20 column chromatography (Sigma Aldrich, Prague, Czech Republic) as described previously [36]. DSB was prepared as described by Gažák et al. [37]. The preparation of 
other dehydro derivatives was published elsewhere [38]. Flavonoids TA and quercetin (QU) were purchased from Sigma Aldrich (Prague, Czech Republic).

Studied Compound Solutions for Hydrophobicity Evaluation

The stock solutions of the studied compounds $\left(1 \mathrm{~g} \mathrm{~L}^{-1}\right)$ were prepared in methanol. To minimize the coelution of analytes during HPLC separation, two mixtures of the studied compounds, at the final concentration of $10 \mathrm{mg} \mathrm{L}^{-1}$, were prepared. Mixture 1 contained SD, diastereomer A of silybin (SB A), diastereomer A of isosilybin (ISB A), DSC, DSD and DISB. Mixture 2 contained TA, mixture of diastereomers A and B of silychristin (SC A and B), QU, diastereomer B of silybin (SB B), diastereomer $B$ of isosilybin (ISB B) and DSB.

\subsection{Chemicals}

Aniline, phenol, 4-chloroaniline, nitrobenzene, benzene, trichloroethylene, toluene, chlorobenzene, and naphthalene, all p.a. grade, were obtained from Lach-Ner (Neratovice, Czech Republic). Buffer components, Dulbecco's Modified Eagle medium without phenol red, and other chemicals were obtained from Sigma-Aldrich (Prague, Czech Republic). Methanol and acetonitrile, both HPLC gradient grades, were obtained from Merck (Darmstadt, Germany). All solutions were prepared using reverse-osmosis deionized water (Ultrapur, Watrex, Prague, Czech Republic). Nitrogen (99.999\%) was obtained from SIAD Czech (Prague, Czech Republic) and helium (99.999\%) from Linde Gas (Prague, Czech Republic).

Reference Compounds for Hydrophobicity Evaluation

Reference compounds (aniline, phenol, 4-chloroaniline, nitrobenzene, benzene, trichloroethylene, toluene, chlorobenzene, and naphthalene) for partition coefficient (log $P_{\text {ow }}$ ) evaluation by chromatographic method were dissolved in methanol and diluted to the appropriate concentration (Table A1). Finally, the mixture of reference compounds was injected into the chromatographic column.

\subsection{HPLC System for Hydrophobicity Evaluation}

The HPLC chromatographic system Dionex UltiMate 3000 (Dionex Corp., Sunnyvale, CA, USA) consisting of a degasser (SRD-3400, 4 DEGASSER CH), a binary pump (HPG-3400SD), an autosampler (WPS-3000 TSL ANALYTICAL), a column compartment (TCC-3000RS) and a diode array detector (DAD-3000, 190-400 nm) was equipped with a Purospher Star RP-18e, $55 \times 2 \mathrm{~mm}, 3 \mu \mathrm{m}$ chromatographic column (Merck, Darmstadt, Germany). The $\log P_{o w}$ values of reference compounds, flavonolignans, TA and QU were determined in gradient elution with mobile phase A: $5 \mathrm{mM}$ phosphate (or $5 \mathrm{mM}$ formate or $5 \mathrm{mM}$ acetate buffer, respectively) with $5 \% \mathrm{MeOH}(v / v)$; in gradient with the mobile phase $\mathrm{B}: 100 \%(v / v) \mathrm{MeOH}$ (linear gradient elution $(\% \mathrm{~B}, v / v): 0 \mathrm{~min}(0 \% \mathrm{~B}), 22 \mathrm{~min}(65 \% \mathrm{~B})$, $25 \min (65 \%(v / v) \mathrm{B}), 25.1 \mathrm{~min}(0 \%(v / v) \mathrm{B}), 30 \mathrm{~min}(0 \%(v / v) \mathrm{B})$. The $\mathrm{pH}$ of mobile phase A was set to $4.5,5.5,6.5,7.5$, and 8.5 for each utilized buffer. The flow rate was $0.3 \mathrm{~mL} \mathrm{~min}^{-1}$, the injection volume was $10 \mu \mathrm{L}$. The temperature of the autosampler as well as the column oven was set to 25 or $32{ }^{\circ} \mathrm{C}$. Detection was carried out at $254 \mathrm{~nm}$. The dead and retention time of the reference compounds as well as studied compounds were measured. The analysis was carried out at least twice.

\subsection{Hydrophobicity Evaluation}

The hydrophobicity (lipophilicity) of compounds was evaluated as the partition coefficient $\left(P_{o w}\right)$, defined as the ratio of the equilibrium concentrations of the dissolved substance in $n$-octanol and water [14].

$$
\log P_{o w}=\log \frac{C \text { n-octanol }}{C \text { water }}
$$

The gradient reverse phase HPLC method [19] using a $C_{18}$ column was used to estimate the log $P_{o w}$ of each studied compound by comparing its retention time $\left(t_{r}\right)$ with the $t_{r}$ of reference substances 
with known $\log P_{o w}$. The capacity factor $(k)$ for the reference compound is calculated using the $t_{\mathrm{r}}$ of reference compound and the dead time of analysis $\left(t_{0}\right)$ :

$$
k=\frac{t_{R}-t_{0}}{t_{0}}
$$

A relation between $k$ and $\log P_{\text {ow }}$ is usually shown in the following equation, which is used for evaluating the $\log P_{\text {ow }}$ of a studied compound [19]:

$$
\log P_{o w}=a+b \times \log k
$$

However, for a more accurate relation between $k$ and $\log P_{o w}$, a polynomial equation of degree 2 (quadratic equation) was applied.

$$
k=a \times\left(\log P_{o w}\right)^{2}+b \times \log P_{o w}+c
$$

For evaluating the effect of $\mathrm{pH}$ on $P_{\text {ow }}$ value, mobile phases A with various $\mathrm{pH}$ levels $(4.5 ; 5.5 ; 6.5$; 7.5 , and 8.5$)$ were utilized. Two temperatures $\left(25\right.$ and $\left.32^{\circ} \mathrm{C}\right)$ were used during the HPLC analysis.

\subsection{In Vitro Skin Penetration (Transdermal Transport)}

Breast tissue specimens were obtained from healthy women undergoing plastic surgery at the Department of Plastic and Aesthetic Surgery (University Hospital in Olomouc). The use of skin tissue complied with the Ethics Committee of the University Hospital in Olomouc and Faculty of Medicine and Dentistry, Palacký University, Olomouc (date: 6.4.2009, ref. number: 41/09). All patients had given their written informed consent. The skin fragments were transported in phosphate buffered saline (PBS) containing antibiotics (penicillin $\left(500 \mathrm{mg} \mathrm{mL}^{-1}\right)$, streptomycin $\left(500 \mathrm{U} \mathrm{mL}^{-1}\right)$ and amphotericin B (1.25 mg mL $\left.\left.{ }^{-1}\right)\right)$. The skin was then washed with PBS three times and used as a membrane in Franz cells. The stratum corneum was oriented into the donor compartment. Liquid Dulbecco's Modified Eagle medium without phenol red and antibiotics was used as the acceptor. The donor compartment was filled with the studied compounds $(2 \mathrm{~mL} ; 50 \mu \mathrm{M})$ in phosphate buffer $(50 \mathrm{mM}, \mathrm{pH}=6.5$ or 8.5$)$ with various concentrations of ethanol $(0,5,10$ or $15 \%(v / v))$. The available diffusion area between the donor and acceptor compartment was $1.77 \mathrm{~cm}^{2}$. The donor compartment and sampling port was closed with parafilm to protect those compartments against evaporation during the experiment. The Franz cells were incubated in a water bath to guarantee a temperature of the donor liquid of 32 ${ }^{\circ} \mathrm{C}$ (temperature of on the human skin surface) and the stirring rate of acceptor liquid was $200 \mathrm{rpm}$. To minimize photodecomposition of test compounds, the incubation was carried out in the dark.

After $24 \mathrm{~h}$, the aliquots of donor and acceptor liquids were collected. The skin was removed from the Franz cell and washed with PBS and cleaned and dried with a cotton mull. The skin tissue was weighed, cut with scissors into small pieces, mixed with an extraction mixture $\left(\mathrm{ACN} / \mathrm{MeOH} / \mathrm{H}_{2} \mathrm{O}, 50: 40: 10, v / v / v\right)$ in the ratio 1:3, and homogenized for $3 \mathrm{~min}$ at 21,500 rpm using a ULTRA-TURRAX ${ }^{\circledR}$ T 25 basic IKA ${ }^{\circledR}$ with a $\mathrm{S} 25 \mathrm{~N}-10 \mathrm{G}$ dispersing element (IKA ${ }^{\circledR}$-Werke Staufen, Germany). The homogenate was centrifuged $\left(12,000 \times g, 10 \mathrm{~min}, 4^{\circ} \mathrm{C}\right)$. The supernatant was then diluted with HPLC mobile phase $\mathrm{A}$ in the ratio 1:1 (an 8-fold final dilution). The donor liquid was finally diluted with HPLC mobile phase A in the ratio 1:9. The acceptor liquid was diluted with HPLC mobile phase A in the ratio 1:1. After centrifugation $\left(12,000 \times g, 10 \mathrm{~min}, 4{ }^{\circ} \mathrm{C}\right)$, samples were analyzed by HPLC (see below).

\subsection{HPLC/HESI-MS of Selected Flavonolignans, Taxifolin and Quercetin in Biological Matrices}

The HPLC chromatographic system was the same as for the hydrophobicity study (Section 3.3) with the following modifications: the monolithic chromatographic column Chromolith Performance RP-18e, $100 \times 2 \mathrm{~mm}$ and monolithic guard column RP-18e, $5 \mathrm{~mm} \times 2 \mathrm{~mm}$ (Merck, Darmstadt, 
Germany) were utilized for the analysis of individual selected flavonolignans/flavonoids in gradient elution with mobile phase A: $\mathrm{MeOH}: \mathrm{H}_{2} \mathrm{O}: \mathrm{CH}_{3} \mathrm{COOH}$ (37:63:0.5); in a gradient with mobile phase B: $100 \% \mathrm{MeOH}$ (linear gradient elution (\%, v): 0-1 $\min (0 \% \mathrm{~B}), 1-3 \min (100 \% \mathrm{~B}), 3-5 \min (100 \% \mathrm{~B})$, $5-5.1 \mathrm{~min}(0 \% \mathrm{~B}), 5.1-8.5 \mathrm{~min}(0 \% \mathrm{~B}))$. The flow rate was $0.3 \mathrm{~mL} \mathrm{~min}^{-1}$, the injection volume was $10 \mu \mathrm{L}$. Before HPLC/HESI-MS analysis, all samples were kept in dark. The temperature of the autosampler was set to $10^{\circ} \mathrm{C}$, and the column oven was set to $30^{\circ} \mathrm{C}$. The HPLC system was on-line connected to the quadrupole ion-trap MS instrument LCQ Fleet (Thermo Scientific, Waltham, MA, USA) operating in a negative as well as a positive heated electron spray ionization (HESI) mode. The HESI-MS parameters selected were: heater temperature $100{ }^{\circ} \mathrm{C}$, capillary temperature $295^{\circ} \mathrm{C}$; in negative/ positive mode: spray voltage $2.9 / 4.0 \mathrm{kV}$, and capillary voltage $-20 /+31 \mathrm{~V}$. Nitrogen was used as the sheath, auxiliary and sweep gas, and helium was used as the collision gas. The sheath, auxiliary and sweep gas flow rates were 35, 5, and 1 (in arbitrary units). The MS spectrum was monitored in the range 150-1000 $\mathrm{m} / \mathrm{z}$ for both ionization modes. The $\mathrm{MS}^{2}$ fragments were isolated from the following parent ions for the negative mode: $301,303,479$, and $481 \mathrm{~m} / z$, respectively; for the positive mode: $303,305,481$, and $483 \mathrm{~m} / z$, respectively. The normalized collision energy was 25 . The quantification of selected flavonolignans, TA, and QU was carried out according to a calibration curve in the range of $0.1-100 \mathrm{ng}$ per injection.

\subsection{Design of Computational Evaluation of Hydrophobicity of Polyphenols}

In order to obtain a computational prediction of the hydrophobicity of flavonolignans, TA, and QU, the $n$-octanol-water partition coefficients were calculated $\left(\log P_{o w, c a l c}\right)$ with the commercial software COSMOtherm 15 [18] based on quantum-chemical calculations and by the freely available online tools AlogP [15] and Molinspiration [16]. AlogP and Molinspiration are based on the analysis of available experimental data; specific conditions such as temperature, $\mathrm{pH}$, etc. cannot be chosen. Data can be interpreted as an estimation of $\log P_{o w, c a l c}$ for mean conditions in which the original thousands of data were obtained. Details about the computational methods used can be found; e.g., in the review by Tetko and Poda [17]. In contrast, in COSMOtherm 15, the parameters for the calculation can be set up. $\log P_{o w, c a l c}$ as a partition coefficient between two phases-water (unionized form) and wet $n$-octanol ( $n$-octanol saturated with water; $27.4 \%$ of mass is formed by water, rest is $n$-octanol)-were calculated at 25 and $32{ }^{\circ} \mathrm{C}$. More details about the calculations can be found in Appendix C. The COSMOmic [39] tool was used for lipid/water partition coefficient calculation $\left(\log P_{l w, c a l c}\right)$. Free energy profiles along the axis perpendicular to the membrane plane from water to the middle of the membrane (Figure 5) were calculated. This can be used further for calculations of $\log P_{l v, c a l c}$ or permeability $(P e r m)$ :

$$
\begin{gathered}
P_{\text {lw,calc }}=\int_{0}^{n}\left(e^{-\frac{\Delta G(z)}{R T}}-\frac{\rho_{(z)}^{\text {water }}}{\rho_{(n)}^{\text {water }}}\right) d z \times \frac{A P L}{M_{\text {lipids }} m_{u}} \\
\text { Perm }=1 / \int_{\text {outside }}^{z} e^{\frac{\Delta G(z)}{R T}} d z
\end{gathered}
$$

where $\Delta G(z)$ is the free energy at depth $z, R$ is the molar gas constant, $T$ is the thermodynamic temperature, $\rho_{(z)}$ water is the water density at depth $z$ and $\rho_{(n)}$ water is the density of bulk water-the integration runs from the middle of the membrane $(z=0)$ through the membrane separated into layers parallel to the membrane plane up to the $n$th layer situated in bulk water. Thanks to the multiplying factor (where APL is the area per lipid, $M_{\text {lipids }}$ is the molecular weight of lipids, $m_{u}$ is the atomic mass constant) the partition coefficient $\log P_{l w, c a l c}$ is in the units used in the experimental work; i.e., $\mathrm{kg}_{\text {(lipid) }} / \mathrm{L}_{\text {(water) }}$.

A fluid dioleoylphosphatidylcholine (DOPC) membrane model was used for lipids, as well as a skin-related solid membrane model. The DOPC membrane model is well established and the calculated partitioning into the DOPC membrane reproduces the experiment well [40]. In order to 
obtain structural inputs for the COSMOmic tool, the lipid bilayers were composed not only with DOPC, but also with ceramide NS24 (CER), or an equimolar mixture of CER, lignoceric acid and cholesterol (CLC). From the free energy profiles on the membranes obtained by COSMOmic, a penetration barrier $\left(\Delta G^{\text {pen }}\right)$ and Perm were also extracted. Detail information about calculation models are mentioned in Appendix C.

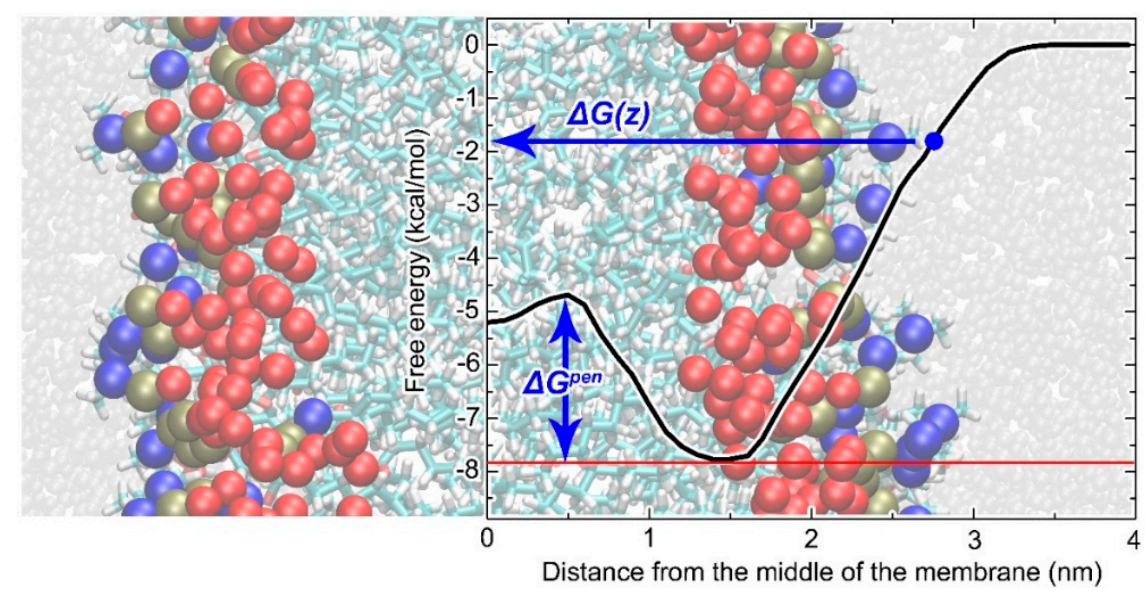

Figure 5. Structure of model membrane and free energy profile of penetration barrier. Lipid membrane constituents: the hydrocarbon chains in the membrane core are represented as cyan and white sticks; oxygen, phosphorus and nitrogen atoms in the DOPC membrane are shown as red, olive and blue balls; water molecules are represented as grey balls. The graph shows the free energy profile of the penetration barrier $\left(\Delta G^{p e n}\right)$ and the free energy at depth $z \Delta G(z)$.

\subsection{Statistical Analysis}

Experimental $\left(\log P_{o w, \exp }\right)$ and theoretical $\left(\log P_{o w, c a l c}, \log P_{l w, c a l c}\right)$ hydrophobicity data were compared in order to observe correlations and differences. For the correlations, MS Excel was used to create a correlation matrix with the Analysis Toolpak add-on providing a correlation coefficient between all the calculated and measured data. Further, a linear regression was done between the data measured in the phosphate buffer at different $\mathrm{pH}$ and the calculated data (also in MS Excel). Apart from correlation coefficients and linear regression equations, the differences between the experimental and calculated values were evaluated as their mean differences MD.

$$
1 / N \sum_{i}^{N}\left|\log P_{o w(l w), c a l c, i}-\log P_{o w, e x p, i}\right|
$$

\section{Conclusions}

In conclusion, $\log P_{\text {ow }}$ values for selected silymarin's flavonolignans, including their respective diastereomers and dehydro derivatives as well as flavonoids taxifolin and quercetin were experimentally determined. For the first time the data for individual diastereomers were determined. The ex vivo permeation of flavonolignans, taxifolin and quercetin through the human skin showed that none of the studied compounds reach the acceptor liquid, and all of them accumulate in the tissue. The computational prediction of $\log P_{o w}$ values and penetration through model lipid membranes for flavonolignans, and their respective dehydro derivatives, taxifolin and quercetin were carried out and compared with experimental values. Although we observed a reliable prediction of $\log P_{\text {ow }}$ values $\left(\mathrm{r}^{2}>0.8\right)$, none of the models worked for all the experimental conditions (at various $\mathrm{pH}$ ). Theoretical tools were unable to clearly distinguish between stereoisomers. The use of lipid membranes for the theoretical estimation of lipophilicity provides a more reliable lipophilicity prediction than $\log P_{\text {ow }}$. Although in silico models cannot yet predict the dermal delivery differences of compounds with very similar structural motifs (for example optical isomers) with the desired level of certainty, they can 
be usefully applied for estimating general lipophilicity trends and skin accumulation predictions. Therefore, the theoretically received data should be still confirmed experimentally.

Both experimental and theoretical tools enabled the studied polyphenols to be divided into two groups based on their skin intake and lipophilicity (taxifolin, silychristin, silydianin vs. silybin, dehydrosilybin, isosilybin). This behavior should be considered during the development of dermatological preparations containing silymarin or its pure flavonolignans as biologically active components.

Author Contributions: P.K., M.P., A.R.S., B.Z. and J.V.; methodology, P.K., M.P., A.R.S. and J.V.; writing-original draft preparation, M.P.; formal analysis, B.Z. and D.B.; resources, J.V. and J.U.; funding acquisition, J.V.; project administration, D.B. and J.U.; writing-review and editing.

Funding: This work was funded by the Czech Grant Agency grants 15-10897S and P208/12/G016 and by the Institutional Support of Palacký University in Olomouc RVO 61989592.

Acknowledgments: We wish to thank Eva Směšná and Iveta Hatalová (University Hospital in Olomouc) for assistance with skin tissue donor recruitment and Benjamin John Watson-Jones for language correction.

Conflicts of Interest: The authors report no conflicts of interest. The authors alone are responsible for the content and writing of the paper.

\section{Appendix A}

Table A1. Reference compounds' $\log P_{o w}$ values and composition of reference compound mixture.

\begin{tabular}{lcc}
\hline Reference Compound & $\log \boldsymbol{P}_{\text {ow }}$ & Amount in Mixture \\
\hline Aniline & 0.9 & $2 \mu \mathrm{L}^{-1}$ \\
Phenol & 1.5 & $10 \mathrm{ng} \mathrm{L}^{-1}$ \\
4-Chloroaniline & 1.8 & $10 \mathrm{ng} \mathrm{L}^{-1}$ \\
Nitrobenzene & 1.9 & $10 \mathrm{ng} \mathrm{L}^{-1}$ \\
Benzene & 2.1 & $30 \mu \mathrm{L}^{-1}$ \\
Trichloroethylene & 2.4 & $50 \mu \mathrm{L}^{-1}$ \\
Toluene & 2.7 & $30 \mu \mathrm{L}^{-1}$ \\
Chlorobenzene & 2.8 & $50 \mu \mathrm{L} \mathrm{L}^{-1}$ \\
Naphthalene & 3.6 & $5 \mathrm{ng} \mathrm{L}^{-1}$ \\
\hline
\end{tabular}

Table A2. Relation between capacity factor $(k)$ and $\log P_{o w}$ of reference compounds in phosphate buffer.

\begin{tabular}{ccccc}
\hline $\mathbf{p H}$ & Linear Equitation & $\mathbf{r}^{2}$ & Quadratic Equitation & $\mathbf{r}^{2}$ \\
\hline 4.5 & $\mathrm{y}=15.564 \mathrm{x}-9.2141$ & 0.8970 & $\mathrm{y}=-7.6607 \mathrm{x}^{2}+54.46 \mathrm{x}-55.269$ & 0.9953 \\
5.5 & $\mathrm{y}=14.935 \mathrm{x}-6.5672$ & 0.8942 & $\mathrm{y}=-7.5071 \mathrm{x}^{2}+53.051 \mathrm{x}-51.698$ & 0.9964 \\
6.5 & $\mathrm{y}=14.855 \mathrm{x}-6.4229$ & 0.8965 & $\mathrm{y}=-7.3626 \mathrm{x}^{2}+52.238 \mathrm{x}-50.685$ & 0.9962 \\
7.5 & $\mathrm{y}=14.895 \mathrm{x}-6.2264$ & 0.8924 & $\mathrm{y}=-7.5201 \mathrm{x}^{2}+53.077 \mathrm{x}-51.435$ & 0.9954 \\
8.5 & $\mathrm{y}=14.99 \mathrm{x}-6.7367$ & 0.8925 & $\mathrm{y}=-7.5849 \mathrm{x}^{2}+53.501 \mathrm{x}-52.335$ & 0.9959 \\
\hline
\end{tabular}

The separation of reference compounds was carried out in $5 \mathrm{mM}$ phosphate buffer with $\mathrm{MeOH}(5 \%, v / v)$, $\mathrm{pH}$ was set in the range of 4.5-8.5 (HPLC mobile phase A) in a linear gradient with $\mathrm{MeOH}$ (100\%; HPLC mobile phase B) at $25^{\circ} \mathrm{C}$. For further conditions, see Materials and Methods section.

Table A3. Hydrophobicity $\left(\log P_{\text {ow,exp }}\right)$ of studied compounds in formate buffers.

\begin{tabular}{lccccc}
\hline \multirow{2}{*}{ Compound } & \multicolumn{5}{c}{$\log \boldsymbol{P}_{\text {ow, exp }}$} \\
\cline { 2 - 6 } & \multicolumn{5}{c}{$\mathbf{p H}$} \\
\cline { 2 - 6 } & $\mathbf{4 . 5}$ & $\mathbf{5 . 5}$ & $\mathbf{6 . 5}$ & $\mathbf{7 . 5}$ & $\mathbf{8 . 5}$ \\
\hline Taxifolin & $1.776 \pm 0.000$ & $1.763 \pm 0.000$ & $1.704 \pm 0.000$ & $1.572 \pm 0.002$ & $0.714 \pm 0.007$ \\
Silychristin A & $2.059 \pm 0.007$ & $2.040 \pm 0.000$ & $2.003 \pm 0.001$ & $1.925 \pm 0.002$ & $1.714 \pm 0.001$ \\
Silydianin & $2.088 \pm 0.003$ & $2.071 \pm 0.000$ & $2.025 \pm 0.000$ & $1.935 \pm 0.001$ & $1.734 \pm 0.000$ \\
Silychristin B & $2.114 \pm 0.007$ & $2.096 \pm 0.000$ & $2.060 \pm 0.000$ & $1.986 \pm 0.002$ & $1.778 \pm 0.006$ \\
Dehydrosilydianin & $2.187 \pm 0.001$ & $2.175 \pm 0.000$ & $2.154 \pm 0.000$ & $2.104 \pm 0.000$ & $1.872 \pm 0.001$ \\
Quercetin & $2.279 \pm 0.001$ & $2.266 \pm 0.000$ & $2.248 \pm 0.001$ & $2.203 \pm 0.001$ & $1.895 \pm 0.000$ \\
\hline
\end{tabular}


Table A3. Cont.

\begin{tabular}{|c|c|c|c|c|c|}
\hline \multirow{3}{*}{ Compound } & \multicolumn{5}{|c|}{$\log P_{\text {ow,exp }}$} \\
\hline & \multicolumn{5}{|c|}{$\mathrm{pH}$} \\
\hline & 4.5 & 5.5 & 6.5 & 7.5 & 8.5 \\
\hline Silybin A & $2.318 \pm 0.001$ & $2.302 \pm 0.000$ & $2.272 \pm 0.000$ & $2.200 \pm 0.001$ & $1.920 \pm 0.000$ \\
\hline Silybin B & $2.350 \pm 0.001$ & $2.335 \pm 0.000$ & $2.304 \pm 0.001$ & $2.229 \pm 0.003$ & $1.959 \pm 0.000$ \\
\hline Dehydrosilychristin & $2.433 \pm 0.002$ & $2.421 \pm 0.000$ & $2.404 \pm 0.005$ & $2.383 \pm 0.000$ & $2.183 \pm 0.001$ \\
\hline Isosilybin A & $2.437 \pm 0.001$ & $2.422 \pm 0.000$ & $2.397 \pm 0.000$ & $2.328 \pm 0.000$ & $2.059 \pm 0.000$ \\
\hline Isosilybin B & $2.459 \pm 0.001$ & $2.444 \pm 0.000$ & $2.415 \pm 0.000$ & $2.348 \pm 0.001$ & $2.081 \pm 0.001$ \\
\hline Dehydrosilybin & $2.947 \pm 0.003$ & $2.936 \pm 0.001$ & $2.928 \pm 0.001$ & $2.898 \pm 0.007$ & $2.661 \pm 0.010$ \\
\hline Dehydroisosilybin & $3.161 \pm 0.009$ & $3.143 \pm 0.002$ & $3.134 \pm 0.004$ & $3.096 \pm 0.004$ & $2.815 \pm 0.004$ \\
\hline
\end{tabular}

The letters A or B in the name of a compound mean that diastereomers of the compound exist and they were separated by a chromatographic system under the applied experimental conditions. Data are presented as mean \pm S.D., $n=4$.

Table A4. Hydrophobicity $\left(\log P_{\text {ow,exp }}\right)$ of studied compounds in acetate buffers.

\begin{tabular}{lccccc}
\hline \multirow{2}{*}{\multicolumn{1}{c}{ Compound }} & \multicolumn{5}{c}{$\log \boldsymbol{P}_{\text {ow, } \text { exp }}$} \\
\cline { 2 - 6 } & $\mathbf{4 . 5}$ & $\mathbf{5 . 5}$ & $\mathbf{6 . 5}$ & $\mathbf{7 . 5}$ & $\mathbf{8 . 5}$ \\
\cline { 2 - 6 } & $1.774 \pm 0.000$ & $1.765 \pm 0.001$ & $1.710 \pm 0.001$ & $1.577 \pm 0.006$ & $0.783 \pm 0.013$ \\
\cline { 2 - 6 } Taxifolin & $2.051 \pm 0.001$ & $2.042 \pm 0.000$ & $1.999 \pm 0.001$ & $1.920 \pm 0.007$ & $1.733 \pm 0.000$ \\
Silychristin A & $2.083 \pm 0.001$ & $2.075 \pm 0.005$ & $2.017 \pm 0.000$ & $1.928 \pm 0.008$ & $1.757 \pm 0.000$ \\
Silydianin & $2.106 \pm 0.001$ & $2.097 \pm 0.001$ & $2.054 \pm 0.000$ & $1.980 \pm 0.007$ & $1.793 \pm 0.000$ \\
Silychristin B & $2.183 \pm 0.001$ & $2.178 \pm 0.002$ & $2.151 \pm 0.001$ & $2.089 \pm 0.008$ & $1.894 \pm 0.001$ \\
Dehydrosilydianin & $2.273 \pm 0.001$ & $2.268 \pm 0.000$ & $2.245 \pm 0.001$ & $2.202 \pm 0.009$ & $1.919 \pm 0.003$ \\
Quercetin & $2.315 \pm 0.000$ & $2.307 \pm 0.006$ & $2.257 \pm 0.001$ & $2.185 \pm 0.008$ & $1.942 \pm 0.001$ \\
Silybin A & $2.347 \pm 0.001$ & $2.337 \pm 0.001$ & $2.289 \pm 0.001$ & $2.217 \pm 0.006$ & $1.979 \pm 0.000$ \\
Silybin B & $2.429 \pm 0.002$ & $2.424 \pm 0.001$ & $2.405 \pm 0.004$ & $2.390 \pm 0.004$ & $2.203 \pm 0.003$ \\
Dehydrosilychristin & $2.434 \pm 0.001$ & $2.428 \pm 0.005$ & $2.377 \pm 0.001$ & $2.310 \pm 0.010$ & $2.079 \pm 0.000$ \\
Isosilybin A & $2.455 \pm 0.001$ & $2.446 \pm 0.000$ & $2.396 \pm 0.001$ & $2.330 \pm 0.010$ & $2.102 \pm 0.000$ \\
Isosilybin B & $2.943 \pm 0.001$ & $2.940 \pm 0.004$ & $2.909 \pm 0.003$ & $2.888 \pm 0.015$ & $2.677 \pm 0.000$ \\
Dehydrosilybin & $3.153 \pm 0.002$ & $3.148 \pm 0.007$ & $3.110 \pm 0.002$ & $3.074 \pm 0.021$ & $2.840 \pm 0.005$ \\
Dehydroisosilybin & &
\end{tabular}

The letters A or B in the name of a compound mean that diastereomers of the compound exist and they were separated by a chromatographic system under the applied experimental conditions. Data are presented as mean \pm S.D., $n=4$.

\section{Appendix B}
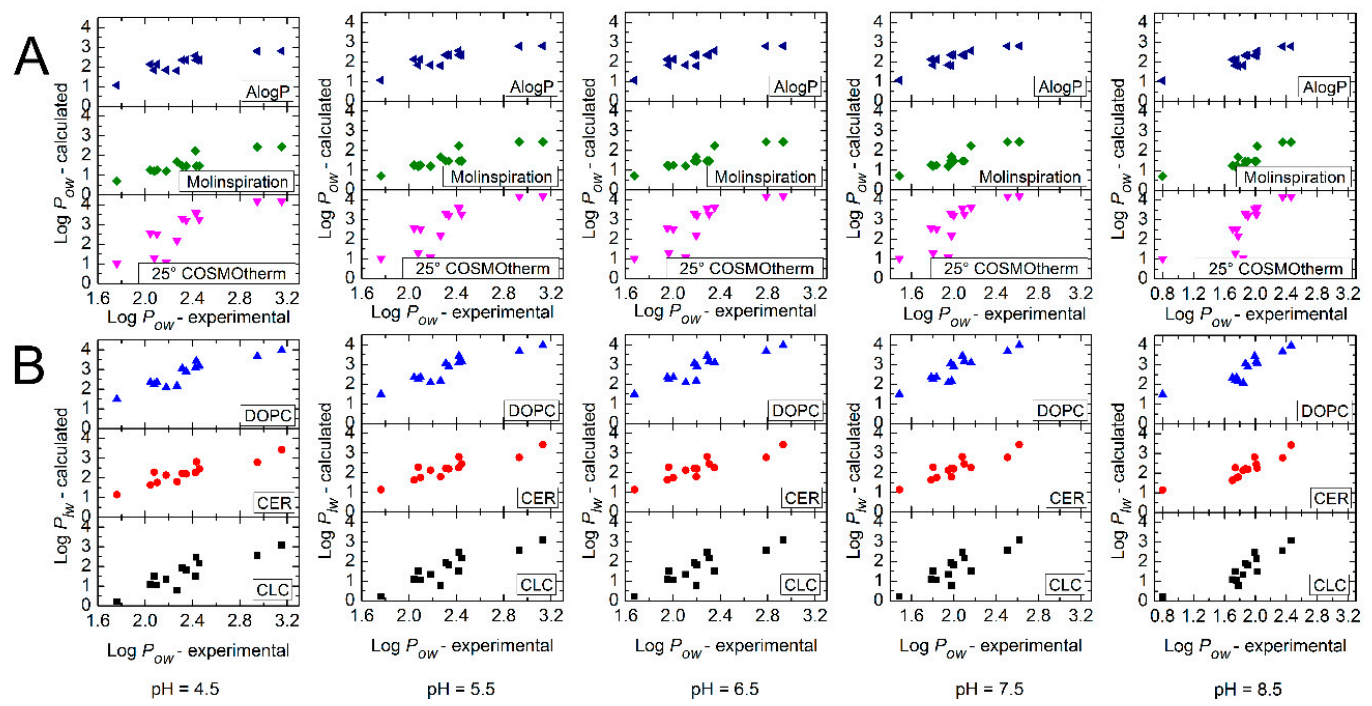

Figure A1. Relation between (A) calculated $\log P_{\text {ow, calc }}$ and experimental $\log P_{\text {ow,exp }}$ measured in phosphate buffer at $\mathrm{pH} 4.5-8.5$; (B) calculated $\log P_{l w, \text { calc }}$ values and experimental $\log P_{\text {ow, exp }}$ measured in phosphate buffer at $\mathrm{pH} 4.5-8.5$. 
Table A5. Correlation coefficient $\left(\mathrm{r}^{2}\right)$ and mean differences (MD) of $n$-octanol/water partition coefficient $\left(\log P_{o w, c a l c}\right)$ to $\log P_{o w, e x p}$ measured at different $\mathrm{pH}$ and calculated lipid/water partition coefficient $\left(\log P_{l w, c a l c}\right)$ in model membranes.

\begin{tabular}{|c|c|c|c|c|c|c|c|}
\hline \multirow{2}{*}{ Parameter } & \multirow{2}{*}{$\mathrm{pH}$} & \multicolumn{3}{|c|}{$\log P_{o w, c a l c}$} & \multicolumn{3}{|c|}{$\log P_{l w, c a l c}$} \\
\hline & & COSMOtherm & Molinspiration & $A \log P$ & CER & DOPC & CLC \\
\hline \multirow{5}{*}{$r^{2}$} & 4.5 & 0.68 & 0.83 & 0.74 & 0.82 & 0.84 & 0.79 \\
\hline & 5.5 & 0.68 & 0.83 & 0.74 & 0.82 & 0.84 & 0.79 \\
\hline & 6.5 & 0.67 & 0.87 & 0.74 & 0.79 & 0.81 & 0.75 \\
\hline & 7.5 & 0.66 & 0.87 & 0.77 & 0.81 & 0.82 & 0.76 \\
\hline & 8.5 & 0.61 & 0.71 & 0.87 & 0.78 & 0.77 & 0.75 \\
\hline \multirow{5}{*}{ MD } & 4.5 & 0.83 & 0.78 & 0.21 & 0.26 & 0.49 & 0.69 \\
\hline & 5.5 & 0.84 & 0.78 & 0.21 & 0.26 & 0.50 & 0.69 \\
\hline & 6.5 & 0.90 & 0.66 & 0.19 & 0.24 & 0.58 & 0.62 \\
\hline & 7.5 & 1.02 & 0.47 & 0.27 & 0.32 & 0.75 & 0.51 \\
\hline & 8.5 & 1.08 & 0.35 & 0.32 & 0.37 & 0.90 & 0.44 \\
\hline
\end{tabular}

Table A6. Correlation coefficients $\left(\mathrm{r}^{2}\right)$ between experimental $n$-octanol/water partition coefficients $\left(\log P_{\text {ow,exp }}\right)$ and skin intake at $\mathrm{pH} 6.5$ and 8.5.

\begin{tabular}{|c|c|c|c|c|c|c|c|c|c|}
\hline & & \multicolumn{4}{|c|}{ Log of Skin Intake, pH 6.5 (without DSB) } & \multicolumn{4}{|c|}{ Log of Skin Intake, pH 8.5} \\
\hline & & \multicolumn{4}{|c|}{$\%$ of Ethanol in Donor Liquid } & \multicolumn{4}{|c|}{$\%$ of Ethanol in Donor Liquid } \\
\hline \multirow{3}{*}{$\log P_{\text {ow,exp }}$} & $\mathrm{pH}$ & 0 & 5 & 10 & 15 & 0 & 5 & 10 & 15 \\
\hline & 6.5 & $0.54(0.94)$ & $\begin{array}{c}0.55 \\
(0.88)\end{array}$ & $\begin{array}{c}0.57 \\
(0.91)\end{array}$ & $\begin{array}{c}0.60 \\
(0.85)\end{array}$ & - & - & - & - \\
\hline & 8.5 & - & - & - & - & 0.77 & 0.63 & 0.83 & 0.67 \\
\hline
\end{tabular}

- Only results obtained at the same $\mathrm{pH}$ were included in the correlation.

Table A7. Correlation coefficients $\left(\mathrm{r}^{2}\right)$ between skin intake and calculated permeability $(\log$ Perm), lipid/water partition coefficient $\left(\log P_{l w, \text { calc }}\right)$ and penetration barrier $\left(\Delta G^{\text {pen }}\right)$ in membrane models.

\begin{tabular}{|c|c|c|c|c|c|c|c|c|c|}
\hline & & \multicolumn{4}{|c|}{ Skin Intake, log Units, pH 6.5 (without QU) } & \multicolumn{4}{|c|}{ Skin Intake, log Units, pH 8.5} \\
\hline & & 0 & 5 & 10 & 15 & 0 & 5 & 10 & 15 \\
\hline \multirow{3}{*}{ log Perm } & CER & 0.95 & 0.93 & 0.82 & 0.94 & 0.94 & 0.94 & 0.76 & 0.63 \\
\hline & DOPC & 0.87 & 0.69 & 0.61 & 0.75 & 0.68 & 0.79 & 0.57 & 0.40 \\
\hline & CLC & 0.94 & 0.92 & 0.83 & 0.94 & 0.95 & 0.93 & 0.79 & 0.66 \\
\hline $\log P_{l w, c a l c}$ & CLC & 0.76 & 0.81 & 0.90 & 0.76 & 0.92 & 0.71 & 0.84 & 0.79 \\
\hline \multirow{3}{*}{$\Delta G^{p e n}(\mathrm{kcal} / \mathrm{mol})$} & CER & 0.84 & 0.80 & 0.56 & 0.89 & 0.82 & 0.94 & 0.65 & 0.53 \\
\hline & DOPC & 0.82 & 0.89 & 0.64 & 0.88 & 0.82 & 0.87 & 0.50 & 0.44 \\
\hline & CLC & 0.83 & 0.79 & 0.56 & 0.88 & 0.82 & 0.92 & 0.61 & 0.52 \\
\hline
\end{tabular}

CER - ceramide, DOPC - dioleoylphosphatidylcholine, CLC—ceramide, lignoceric acid and cholesterol mixture. The cells are coloured according to the $\mathrm{r}^{2}$ values based on the displayed colour scale. The linear regression equations for skin intake at $\mathrm{pH} 8.5$ on model membranes were: CER: $\log$ (Intake to skin) $=0.76 * \log P_{l w, \text { calc, CER }}+2.43$. DOPC: $\log ($ Intake to skin $)=0.63 * \log P_{l w, c a l c, D O P C}+2.36$. CLC: $\log ($ Intake to skin $)=0.54 * \log P_{l w, \text { calc }, \text { CLC }}+3.20$.

\section{Appendix C}

\section{Calculation Details:}

In order to obtain a computational prediction of the hydrophobicity of flavonolignans, TA, and QU, the $n$-octanol-water partition coefficients were calculated $\left(\log P_{o w, c a l c}\right)$ with the commercial software COSMOtherm 15 software [18] based on quantum-chemical calculations and by the freely available online tools AlogP [15] and Molinspiration [16].

First, the molecular structures were downloaded as pdf files from Pubchem [41]. For COSMOtherm calculations, the same workflow was used as recently in Navrátilová et al. [42]. 
Individual conformers were generated using the Schrodinger software package $[43,44]$ and for each conformer its vacuum energy and sigma-surfaces were calculated. These were calculated at the BP/TZVP-fine level of theory both for vacuum and cosmo solvent calculation with Turbomole 6.3 [45]. For the $\log P_{\text {ow }}$ calculation, COSMOtherm provides a pre-defined setup for partitioning between two fluid phases, where octanol is modelled as a wet octanol, meaning $27.4 \%$ of its mass is water, reflecting experimentally more relevant conditions than using dry $100 \%$ octanol. The partitioning calculation was performed at 25 and $32{ }^{\circ} \mathrm{C}$. Generally, COSMOtherm calculates the thermodynamic properties of fluid phases, including the partition of substances between variously composed phases. However, a full description of COSMOtherm's principles is outside the scope of this paper and was described; e.g., by Klamt [46].

For lipid/water partition coefficient calculations, we used COSMOmic [39]. The semi-continuous tool of COSMOtherm uses a lipid bilayer structure/s as an input, separates them into layers and calculates the partition coefficient of the drug into each location (into each layer taking into account the possibility of interactions of the drug with neighboring layers by its rotation). The partition coefficients into individual locations can be easily converted into a free energy profile or into the general lipid/water partition coefficient $\log P_{l w}$. Fluid dioleoylphosphatidylcholine (DOPC) membrane models as well as skin-related solid membrane models were used. The DOPC membrane model is well established and the calculated overall partitioning into phosphatidylcholine membranes reproduces the experiment well. The solid membrane models, ceramide-based ones, do not reflect the basic COSMOtherm requirement for work with fluid phases, but can be also used for estimation drug/lipid interactions, taking into account the need for free energy barrier re-evaluation.

Our previous MD simulations of lipid bilayers consisted of DOPC, ceramide NS24 (CER) and an equimolar mixture of ceramide NS24, lignoceric acid and cholesterol (referred to below as the CLC-mixture) were used. The distribution of individual lipid and water atoms during the last $100 \mathrm{~ns}$ of simulations and the averaged atomic distributions of each of the membranes were monitored. Further, cosmo surfaces (the inducted charge distribution of surface segments) on each of the lipid types (BP/TZVP-fine level of theory) were calculated and COSMOmic was run. The permeability coefficient $\log$ Perm was also extracted from the free energy profiles on the membranes obtained with COSMOmic.

\section{References}

1. Abd, E.; Yousef, S.A.; Pastore, M.N.; Telaprolu, K.; Mohammed, Y.H.; Namjoshi, S.; Grice, J.E.; Roberts, M.S. Skin models for the testing of transdermal drugs. Clin. Pharmacol. 2016, 8, 163-176. [CrossRef] [PubMed]

2. N'Da, D.D. Prodrug strategies for enhancing the percutaneous absorption of drugs. Molecules 2014, 19, 20780-20807. [CrossRef] [PubMed]

3. Bijak, M. Silybin, a Major Bioactive Component of Milk Thistle (Silybum marianum L. Gaernt.)—Chemistry, Bioavailability, and Metabolism. Molecules 2017, 22, 1942. [CrossRef] [PubMed]

4. Chambers, C.S.; Holečková, V.; Petrásková, L.; Biedermann, D.; Valentová, K.; Buchta, M.; Křen, V. The silymarin composition and why does it matter??? Food Res. Int. 2017, 100, 339-353. [CrossRef] [PubMed]

5. Biedermann, D.; Buchta, M.; Holečková, V.; Sedlák, D.; Valentová, K.; Cvačka, J.; Bednárová, L.; Křenková, A.; Kuzma, M.; Škuta, C.; et al. Silychristin: Skeletal Alterations and Biological Activities. J. Nat. Prod. 2016, 79, 3086-3092. [CrossRef]

6. Chambers, C.S.; Valentova, K.; Kren, V. “Non-Taxifolin” Derived Flavonolignans: Phytochemistry and Biology. Curr. Pharm. Des. 2015, 21, 5489-5500. [CrossRef] [PubMed]

7. Csupor, D.; Csorba, A.; Hohmann, J. Recent advances in the analysis of flavonolignans of Silybum marianum. J. Pharm. Biomed. Anal. 2016, 130, 301-317. [CrossRef] [PubMed]

8. Singh, R.P.; Agarwal, R. Mechanisms and preclinical efficacy of silibinin in preventing skin cancer. Eur. J. Cancer 2005, 41, 1969-1979. [CrossRef] [PubMed]

9. Vaid, M.; Katiyar, S.K. Molecular mechanisms of inhibition of photocarcinogenesis by silymarin, a phytochemical from milk thistle (Silybum marianum L. Gaertn.) (Review). Int. J. Oncol. 2010, 36, 1053-1060. [CrossRef] [PubMed] 
10. Han, M.H.; Yoon, W.K.; Lee, H.; Han, S.B.; Lee, K.; Park, S.K.; Yang, K.H.; Kim, H.M.; Kang, J.S. Topical application of silymarin reduces chemical-induced irritant contact dermatitis in BALB/c mice. Int. Immunopharmacol. 2007, 7, 1651-1658. [CrossRef] [PubMed]

11. Altaei, T. The treatment of melasma by silymarin cream. BMC Dermatol. 2012, 12, 1-6. [CrossRef]

12. Sharifi, R.; Rastegar, H.; Kamalinejad, M.; Dehpour, A.R.; Tavangar, S.M.; Paknejad, M.; Mehrabani Natanzi, M.; Ghannadian, N.; Akbari, M.; Pasalar, P. Effect of topical application of silymarin (Silybum marianum) on excision wound healing in albino rats. Acta Med. Iran. 2012, 50, 583-588. [PubMed]

13. OECD Guideline for the Testing of Chemicals. Test No. 107: Partition Coefficient (n octanol/water), Shake Flask Method. 27 July 1995. Available online: https:/ / www.oecd-ilibrary.org/environment/test-no107-partition-coefficient-n-octanol-water-shake-flask-method_9789264069626-en (accessed on 20 May 2018).

14. OECD Guidelines for the Testing of Chemicals, Section 1, Physical-Chemical properties. Test No. 117: Partition Coefficient (n-octanol/water), HPLC Method. 23 November 2004. Available online: https:/ / www.oecd-ilibrary.org/environment/test-no-117-partition-coefficient-n-octanol-waterhplc-method_9789264069824-en (accessed on 20 May 2018).

15. Tetko, I.V.; Gasteiger, J.; Todeschini, R.; Mauri, A.; Livingstone, D.; Ertl, P.; Palyulin, V.A.; Radchenko, E.V.; Zefirov, N.S.; Makarenko, A.S.; et al. Virtual computational chemistry laboratory-design and description. J. Comput. Aided Mol. Des. 2005, 19, 453-463. [CrossRef]

16. Molinspiration Cheminformatics. Available online: http://www.molinspiration.com/ (accessed on 20 May 2018).

17. Tetko, I.V.; Poda, G.I. Prediction of Log P with Property-Based Methods. In Molecular Drug Properties: Measurement and Prediction; Wiley-VCH: Weinheim, Germany, 2007; pp. 381-406, ISBN 978-3-527-31755-4.

18. Eckert, F.; Klamt, A. COSMOlogic GmbH \& Co. KG: Leverkusen, Germany, 2013.

19. Valkó, K. Application of high-performance liquid chromatography based measurements of lipophilicity to model biological distribution. J. Chromatogr. A 2004, 1037, 299-310. [CrossRef] [PubMed]

20. Maroziene, A.; Kliukiene, R.; Sarlauskas, J.; Cenas, N. Inhibition of phthalocyanine-sensitized photohemolysis of human erythrocytes by polyphenolic antioxidants: Description of quantitative structure-activity relationships. Cancer Lett. 2000, 157, 39-44. [CrossRef]

21. Rothwell, J.A.; Day, A.J.; Morgan, M.R. Experimental determination of octanol-water partition coefficients of quercetin and related flavonoids. J. Agric. Food Chem. 2005, 53, 4355-4360. [CrossRef]

22. Gazák, R.; Svobodová, A.; Psotová, J.; Sedmera, P.; Prikrylová, V.; Walterová, D.; Kren, V. Oxidised derivatives of silybin and their antiradical and antioxidant activity. Bioorg. Med. Chem. 2004, 12, 5677-5687. [CrossRef]

23. Zeng, Q.P.; Liu, Z.H.; Huang, A.W.; Zhang, J.; Song, H.T. Preparation and characterization of silymarin synchronized-release microporous osmotic pump tablets. Drug Des. Devel. Ther. 2016, 10, 519-531. [CrossRef]

24. Meloun, M.; Burkoňová, D.; Syrový, T.; Vrána, A. Thermodynamic dissociation constants of silychristin, silybin, silydianin and mycophenolate by the regression analysis of spectrophotometric data. Anal. Chim Acta. 2003, 486, 125-141. [CrossRef]

25. Shubina, V.S.; Shatalina, Y.V. Absorption Spectroscopy Study of Acid-Base and Metal-Binding Properties of Flavanones. J. Appl. Spectrosc. 2013, 80, 761-766. [CrossRef]

26. Herrero-Martínez, J.M.; Sanmartin, M.; Rosés, M.; Bosch, E.; Ràfols, C. Determination of dissociation constants of flavonoids by capillary electrophoresis. Electrophoresis 2005, 26, 1886-1895. [CrossRef] [PubMed]

27. Garrido, N.M.; Queimada, A.J.; Jorge, M.; Macedo, E.A.; Economou, I.G. 1-Octanol/Water Partition Coefficients of N-Alkanes from Molecular Simulations of Absolute Solvation Free Energies. J. Chem. Theory Comput. 2009, 5, 2436-2446. [CrossRef] [PubMed]

28. Sun, H. (Ed.) Quantitative Structure-Property Relationships Models for Lipophilicity and Aqueous Solubility. In A Practical Guide to Rational Drug Design; Elsevier: Cambridge, UK, 2016; pp. 193-223.

29. Ekins, S.; Mestres, J.; Testa, B. In Silico Pharmacology for Drug Discovery: Methods for Virtual Ligand Screening and Profiling. Br. J. Pharmacol. 2007, 152, 9-20. [CrossRef] [PubMed]

30. Mannhold, R.; Poda, G.I.; Ostermann, C.; Tetko, I.V. Calculation of molecular lipophilicity: State-of-the-art and comparison of $\log$ P methods on more than 96,000 compounds. J. Pharm. Sci. 2009, 98, 861-893. [CrossRef] [PubMed]

31. Benson, H.A.E. Skin Structure, Function, and Permeation. In Topical and Transdermal Drug Delivery: Principles and Practice; Benson, H.A.E., Watkinson, A.C., Eds.; John Wiley \& Sons, Inc.: Hoboken, NJ, USA, 2012. 
32. Wang, W.; Sun, C.; Mao, L.; Ma, P.; Liu, F.; Yang, L.; Gao, Y. The biological activities, chemical stability, metabolism and delivery systems of quercetin: A review. Trends Food Sci. Technol. 2016, 56, 21-38. [CrossRef]

33. Hung, C.F.; Lin, Y.K.; Zhang, L.W.; Chang, C.H.; Fang, J.Y. Topical delivery of silymarin constituents via the skin route. Acta Pharmacol. Sin. 2010, 31, 118-126. [CrossRef] [PubMed]

34. Jung, E.C.; Maibach, H.I. Animal models for percutaneous absorption. J. Appl. Toxicol. 2015, 35, 1-10. [CrossRef]

35. Monti, D.; Gažák, R.; Marhol, P.; Biedermann, D.; Purchartová, K.; Fedrigo, M.; Riva, S.; Křen, V. Enzymatic Kinetic Resolution of Silybin Diastereoisomers. J. Nat. Prod. 2010, 73, 613-619. [CrossRef]

36. Křenek, K.; Marhol, P.; Peikerová, Ž.; Křen, V.; Biedermann, D. Preparatory separation of the silymarin flavonolignans by Sephadex LH-20 gel. Food Res. Int. 2014, 65, 115-120. [CrossRef]

37. Gažák, R.; Trouillas, P.; Biedermann, D.; Fuksová, K.; Marhol, P.; Kuzma, M.; Křen, V. Base-catalyzed oxidation of silybin and isosilybin into 2,3-dehydro derivatives. Tetrahedron Lett. 2013, 54, 315-317. [CrossRef]

38. Pyszková, M.; Biler, M.; Biedermann, D.; Valentová, K.; Kuzma, M.; Vrba, J.; Ulrichová, J.; Sokolová, R.; Mojovic, M.; Popovic-Bijelic, A.; et al. Flavonolignan 2,3-dehydroderivatives: Preparation, antiradical and cytoprotective activity. Free Rad. Biol. Med. 2016, 90, 114-125. [CrossRef]

39. Klamt, A.; Huniar, U.; Spycher, S.; Keldenich, J. COSMOmic: A mechanistic approach to the calculation of membrane-water partition coefficients and internal distributions within membranes and micelles. J. Phys. Chem. B 2008, 112, 12148-12157. [CrossRef] [PubMed]

40. Ingram, T.; Storm, S.; Kloss, L.; Mehling, T.; Jakobtorweihen, S.; Smirnova, I.V. Prediction of micelle/water and liposome/water partition coefficients based on molecular dynamics simulations, COSMO-RS, and COSMOmic. Langmuir. 2013, 29, 3527-3537. [CrossRef] [PubMed]

41. Pubchem. Available online: https:// pubchem.ncbi.nlm.nih.gov/ (accessed on 20 May 2018).

42. Navrátilová, V.; Paloncýová, M.; Berka, K.; Mise, S.; Haga, Y.; Matsumura, C.; Sakaki, T.; Inui, H.; Otyepka, M. Molecular Insights into the Role of a Distal F240A Mutation That Alters CYP1A1 Activity towards Persistent Organic Pollutants. BBA Gen. Subj. 2017, 1861, 2852-2860. [CrossRef]

43. Schrödinger Release 2015-1, Maestro. Schrödinger; LLC: New York, NY, USA, 2015.

44. Small-Molecule Drug Discovery Suite 2015-4, Schrödinger; LLC: New York, NY, USA, 2016.

45. TURBOMOLE: Program Package for ab initio Electronic Structure Calculations. Available online: http: / / www.turbomole.com (accessed on 20 May 2018).

46. Klamt, A. The COSMO and COSMO-RS Solvation Models. Wiley Interdiscip. Rev. Comput. Mol. Sci. 2011, 1, 699-709. [CrossRef]

Sample Availability: Studied compounds are available from the authors.

(C) 2018 by the authors. Licensee MDPI, Basel, Switzerland. This article is an open access article distributed under the terms and conditions of the Creative Commons Attribution (CC BY) license (http:/ / creativecommons.org/licenses/by/4.0/). 